\title{
PACAP/PAC ${ }_{1}$ R signaling modulates acetylcholine release at neuronal nicotinic synapses
}

\author{
Phyllis C. Pugh, Ph.D. \\ University of Alabama, Dept. of Neurobiology, Birmingham, AL 35294
}

Selwyn S. Jayakar, Ph.D., and University of Toledo College of Medicine, Department of Neurosciences, Toledo, $\mathrm{OH} 43614-5804$

Joseph F. Margiotta, Ph.D. University of Toledo College of Medicine, Department of Neurosciences Mail Stop \#1007, Block HS 108, 3000 Arlington Ave., Toledo, $\mathrm{OH} 43614-5804$

\begin{abstract}
Neuropeptides collaborate with conventional neurotransmitters to regulate synaptic output. Pituitary adenylate cyclase-activating polypeptide (PACAP) co-localizes with acetylcholine in presynaptic nerve terminals, is released by stimulation, and enhances nicotinic acetylcholine receptor- (nAChR-) mediated responses. Such findings implicate PACAP in modulating nicotinic neurotransmission, but relevant synaptic mechanisms have not been explored. We show here that PACAP acts via selective high-affinity G-protein coupled receptors $\left(\mathrm{PAC}_{1} \mathrm{Rs}\right)$ to enhance transmission at nicotinic synapses on parasympathetic ciliary ganglion (CG) neurons by rapidly and persistently increasing the frequency and amplitude of spontaneous, impulse-dependent nicotinic excitatory postsynaptic currents (sEPSCs). Of the canonical adenylate cyclase (AC) and phospholipase-C (PLC) transduction cascades stimulated by $\mathrm{PACAP} / \mathrm{PAC}_{1} \mathrm{R}$ signaling, only $\mathrm{AC}$-generated signals are critical for synaptic modulation since the increases in sEPSC frequency and amplitude were mimicked by 8-BromocAMP, blocked by inhibiting AC or cAMP-dependent protein kinase (PKA), and unaffected by inhibiting PLC. Despite its ability to increase agonist-induced nAChR currents, PACAP failed to influence nAChR-mediated impulse-independent miniature EPSC amplitudes (quantal size). Instead, evoked transmission assays reveal that $\mathrm{PACAP} / \mathrm{PAC}_{1} \mathrm{R}$ signaling increased quantal content, indicating it modulates synaptic function by increasing vesicular $\mathrm{ACh}$ release from presynaptic terminals. Lastly, signals generated by the retrograde messenger, nitric oxide- (NO-) are critical for the synaptic modulation since the PACAP-induced increases in spontaneous EPSC frequency, amplitude and quantal content were mimicked by NO donor and absent after inhibiting NO synthase (NOS). These results indicate that PACAP/PAC $\mathrm{P}_{1}$ activation recruits AC-dependent signaling that stimulates NOS to increase NO production and control presynaptic transmitter output at neuronal nicotinic synapses.
\end{abstract}

Corresponding Author: Joseph F. Margiotta, Ph.D. Tel: 419-383-4119; Fax: 419-383-3008; joseph.margiotta @ utoledo.edu. Project Address: University of Toledo College of Medicine, Department of Neurosciences Block HS 108, 3000 Arlington Ave., Mail Stop \#1007, Toledo, OH 43614-5804.

Dedication: This paper is dedicated to the memory of Desiree Pardi MD/PhD who pioneered studies of PACAP in this laboratory for her $\mathrm{PhD}$ thesis research. Desiree died peacefully on September 6, 2009.

Publisher's Disclaimer: This is a PDF file of an unedited manuscript that has been accepted for publication. As a service to our customers we are providing this early version of the manuscript. The manuscript will undergo copyediting, typesetting, and review of the resulting proof before it is published in its final citable form. Please note that during the production process errors may be discovered which could affect the content, and all legal disclaimers that apply to the journal pertain. 


\section{Keywords}

Ciliary ganglion; quantal analysis; patch-clamp; neuropeptide; nitric oxide

\section{INTRODUCTION}

Neuropeptides activate specific cell-surface receptors, triggering intracellular signals that regulate an array of cellular functions. Pituitary adenylate-cyclase activating polypeptide (PACAP) is a 38 amino acid neuropeptide first isolated from ovine hypothalamus and now known to be widely expressed throughout the nervous system (Miyata et al., 1989; Hannibal, 2002). PACAP modulates the function of ion channels and synaptic components, provides neuroprotective and neurotrophic support, and potently alters neuronal gene expression (Vaudry et al., 2000; Sumner and Margiotta, 2008). In parasympathetic ciliary ganglion (CG) neurons, PACAP acts via selective, high-affinity, G-protein coupled receptors $\left(\mathrm{PAC}_{1} \mathrm{Rs}\right)$ that activate both adenylate cyclase- (AC-) and phospholipase-C- (PLC-) dependent transduction cascades (Margiotta and Pardi, 1995; Pardi and Margiotta, 1999). The resultant signaling rapidly regulates both heteromeric nicotinic $\mathrm{ACh}$ receptors (containing $\alpha 3, \alpha 5, \beta 4, \pm \beta 2$ subunits; $\alpha 3 *$-nAChRs) and homomeric $\alpha 7$-nAChRs, and mobilizes intracellular calcium (Margiotta and Pardi, 1995; Pardi and Margiotta, 1999; Woo and Margiotta, 2007). Over the long term, PACAP-generates activity- and AC-dependent signals that support neuronal survival by blunting apoptosis (Pugh and Margiotta, 2006). Recent studies indicate PACAP/ $\mathrm{PAC}_{1} \mathrm{R}$ signaling also induces time-dependent alterations in gene expression related to development and synaptic function in both sympathetic (Girard et al., 2004; Braas et al., 2007) and CG neurons (Sumner and Margiotta, 2008). Interestingly, PACAP co-localizes with $\mathrm{ACh}$ in presynaptic nerve terminals in adrenal gland, sympathetic, and ciliary ganglia (Hamelink et al., 2002; Ermilov et al., 2004; Sumner et al., 2004). Taken together, these findings highlight PACAP's pleiotropic actions, and suggest its activity- and time-dependent influences on local neuron targets in vivo involve regulation of synaptic function.

The expectation that PACAP would regulate the function of neuronal nicotinic synapses was tested in the present experiments. Evidence for activity-dependent PACAP release was obtained by showing that PACAP immunoreactivity disappears from presynaptic cholinergic terminals in the $\mathrm{CG}$ after treatment with depolarizing $\left[\mathrm{K}^{+}\right]_{\text {out }}$. To determine its influence on nicotinic synapses, PACAP was applied to CG cultures where the neurons recapitulate key developmental milestones, including morphological specialization, expression of nAChRs, and elaboration of nicotinic synapses that mimic their counterparts in vivo (Ravdin and Berg, 1979; Margiotta and Berg, 1982; Role and Fischbach, 1987; Chen et al., 2001). PACAP dramatically enhanced spontaneous synaptic activity in the cultures, increasing the average frequency and amplitude of spontaneous, impulse-dependent excitatory postsynaptic currents (sEPSCs) recorded from CG neurons within minutes. The PACAP-induced changes in synaptic function required $\mathrm{PAC}_{1} \mathrm{R}$ signaling via $\mathrm{AC}$ and $\mathrm{PKA}$. Measurements of repetitive spike firing characteristics, and analysis of quantal EPSC components reveal that PACAP enhanced synaptic activity neither by increasing excitability nor by upregulating postsynaptic $\mathrm{nAChRs}$ (quantal size) but did so by increasing vesicular $\mathrm{ACh}$ release (quantal content) from presynaptic terminals. Further, the PACAP-induced increase in quantal content required activation of the gaseous messenger, nitric oxide (NO). These results are consistent with the pleiotropic actions of PACAP, and reveal an unexpected relevance for PACAP/PAC $\mathrm{P}_{1} \mathrm{R}$ signaling via $\mathrm{NO}$ to regulate $\mathrm{ACh}$ release from presynaptic terminals at neuronal nicotinic synapses. 


\section{METHODS}

\section{Cell Culture}

Neuronal cultures were prepared from embryonic day 8 (E8) ciliary ganglia as previously described (Chen et al., 2001). Briefly, ganglia were treated with trypsin $\left(0.025 \%, 15 \mathrm{~min}, 37^{\circ}\right.$ C) and CG neurons dispersed by trituration and grown on coated glass coverslips. The growth medium consisted of Eagle's minimum essential medium supplemented with $2 \mathrm{mM}$ glutamine, $100 \mathrm{U} / \mathrm{ml}$ penicillin, $100 \mu \mathrm{g} / \mathrm{ml}$ streptomycin, and $10 \%$ heat-inactivated horse serum (MEM, all components from Invitrogen, Rockville, MD) and with freshly-prepared E17 chick eye extract (3\% v/v, MEM/eye). Glass coverslips ( $\# 1,12 \mathrm{~mm}$, Fisher Scientific) were acid-washed and coated with $0.2 \mathrm{mg} / \mathrm{ml}$ poly-D-ornithine and $30 \mathrm{ng} / \mathrm{ml}$ mouse laminin (Collaborative Biomedical, Bedford, MA). Coverslip cultures were maintained for up to $7 \mathrm{~d}$ in $16 \mathrm{~mm}$ multiwell plates at $37^{\circ} \mathrm{C}$ in $95 \%$ air and $5 \% \mathrm{CO}_{2}$, and the culture medium replenished every $2-3 \mathrm{~d}$.

\section{Microscopy}

To localize PACAP and assess its depletion, E19 ciliary ganglia were incubated (30 min, $22^{\circ}$ C) in MEM containing normal $(5 \mathrm{mM})$ or depolarizing $(50 \mathrm{mM}) \mathrm{KCl}$, and then processed using a whole ganglion imaging protocol (Rubio et al., 2005) modified to accommodate PACAP signal amplification \{Tyramide signal amplification (TSA) kit, Molecular Probes/Invitrogen, Carlsbad, CA \}. Control and KCl-treated ganglia were fixed with $4 \%$ paraformaldehyde freshly prepared in $0.1 \mathrm{M}$ Phosphate buffered saline (PBS, $\left.30 \mathrm{~min}, 22^{\circ} \mathrm{C}\right)$, washed in PBS $\left(16 \mathrm{~h}, 4^{\circ} \mathrm{C}\right)$, and incubated in PBS containing $3 \% \mathrm{H}_{2} \mathrm{O}_{2}\left(1 \mathrm{~h}, 22^{\circ} \mathrm{C}\right)$ to quench endogenous peroxidase activity. Ganglia were then incubated $\left(16 \mathrm{~h}, 4^{\circ} \mathrm{C}\right)$ in block solution (PBS containing $0.1 \%$ Triton $\mathrm{X}-100$, and $1 \%$ TSA kit block reagent) with Avidin D (150 $\mu \mathrm{l} / \mathrm{ml}$; Avidin/Biotin Blocking Kit; Vector Laboratories, Burlingame, CA) added to mask endogenous biotin. Ganglia were washed in PBS and incubated with antibodies recognizing the presynaptic marker Synapsin-I (pAb1543, 1:250, Chemicon/Millipore, Billerica, MA) and PACAP-38 (mAbJHH1, 1:100, provided by Jens Hannibal, University of Copenhagen) in block solution containing $150 \mu \mathrm{l} / \mathrm{ml}$ Biotin $\left(16 \mathrm{~h}, 4^{\circ} \mathrm{C}\right)$. Next, ganglia were washed in PBS, and Synapsin-I and PACAP labeling were detected using Alexa Fluor 488-conjugated goat anti-rabbit IgG (Molecular Probes/ Invitrogen, Carlsbad, CA) and biotinylated goat anti-mouse IgG (Kirkegaard Perry Laboratories, Gaithersburg, MD), respectively (both at 1:200 in block solution lacking Triton $\left.\mathrm{X}-100,16 \mathrm{~h}, 4^{\circ} \mathrm{C}\right)$. To amplify the PACAP signal, ganglia were washed in PBS, incubated in Triton-free block solution containing horseradish peroxidase-conjugated streptavidin (1:100, TSA kit, $1 \mathrm{~h}, 22^{\circ} \mathrm{C}$ ), washed, incubated in amplification buffer with $0.0015 \% \mathrm{H}_{2} \mathrm{O}_{2}$ and Alexa Fluor 546-labeled tyramide (1:100, TSA kit, $\left.10 \mathrm{~min}, 22^{\circ} \mathrm{C}\right)$. Ganglia were washed again, mounted in Vectashield (Vector Laboratories; Burlingame, CA) and examined using an Olympus BX51 microscope equipped with a 1.2 NA 60X objective, and a BioRad Radiance2000 laser scanning confocal system (Carl Zeiss MicroImaging, Thornwood, NY). Optical Z-sections were acquired sequentially through the ganglia in $1.0 \mu \mathrm{m}$ steps using BioRad Lasersharp software, with power and gain settings that minimized pixel saturation and produced no detectable bleed-through between $\operatorname{Ar}(488 \mathrm{~nm})$ and Green HeNe $(543 \mathrm{~nm})$ laser channels. Images were analyzed using ImageJ (v1.40g) (Rasband, 2004) plugins to evaluate signal intensities and colocalization (by Mander's coefficients, M).

\section{Electrophysiology}

After $5 \mathrm{~d}$ in culture, recordings were obtained from $\mathrm{CG}$ neurons bathed at $22^{\circ} \mathrm{C}$ in a recording solution containing (in $\mathrm{mM}$ ): $145 \mathrm{NaCl}, 5.3 \mathrm{KCl}$, 5 HEPES, 5.4 Glucose, $0.8 \mathrm{MgSO}_{4}, 2$ $\mathrm{CaCl}_{2}$ (RS) supplemented with $10 \%$ heat inactivated horse-serum (RS ${ }^{\mathrm{hs}} ; \mathrm{pH}$ 7.4). Patch pipettes (2-4 MO) were fabricated from Corning 8161 glass tubing and filled with (in $\mathrm{mM}$ ) 145.6 CsCl, 0.6 $\mathrm{CaCl}_{2}, 2.0$ EGTA, 15.4 glucose, and 5.0 Na-HEPES (pH 7.3). In most 
experiments, membrane currents were acquired from neuron somas in the whole-cell configuration using Axopatch 1B or 200B patch clamps (Molecular Devices, Sunnyvale, CA) and digitized, usually at $100 \mu$ s intervals, using an ITC-16 interface and Pulse 8.6.3 software (InstruTECH/HEKA, Bellmore, NY) controlled from a Macintosh G4 computer running OS-9. The standard holding potential $\left(\mathrm{V}_{\text {hold }}\right)$ was $-70 \mathrm{mV}$, and neurons typically had input resistances $>500 \mathrm{M} \Omega$; those displaying peak voltage-activated $\mathrm{Na}^{+}$currents $<150 \mathrm{pA} / \mathrm{pF}(150 \mathrm{pA} / \mathrm{pF} X$ $20 \mathrm{pF}=3000 \mathrm{pA}$ ) were excluded.

Synaptic function was assessed by analyzing both spontaneous and stimulus-evoked EPSCs. Spontaneously arising EPSCs (sEPSCs) were acquired without stimulation, as previously described (Chen et al., 2001). In other experiments, EPSCs were evoked (eEPSCs) by applying "en-passant" stimuli to neurite fasicles converging on individual CG neuron somas held in whole-cell mode. To do so, bipolar electrodes were fabricated from theta-glass capillary tubing (TG150-4, Warner Instruments, Hamden, CT) pulled to 1-3 $\mu$ m overall diameter, the barrels filled with RS, and the electrode mounted in a ported theta-glass holder (THS-F15PH, Warner Instruments, Hamden, CT) connected to an isolated stimulator (Model 2100, A-M Systems, Carlsborg, WA). Neurite fasicles were isolated by partially drawing them into the electrode barrels using gentle suction, and voltage pulses (100-300 $\mu \mathrm{sec})$ applied between the barrels. The stimulus intensity was adjusted to activate single axons, as determined by "minimal stimulation" criteria (e.g., further reducing stimulus intensity elicited eEPSCs in the follower neuron less than $25 \%$ of the time). We considered the criteria satisfied when stimuli were just sufficient to evoke EPSCs that (1) activated with brief constant delay, (2) activated to full amplitude without notches indicative of a secondary component, and (3) had amplitudes and kinetics matching those of sEPSCs in the same culture. Miniature EPSCs (mEPSCs) were obtained either from spontaneous synaptic events acquired while blocking $\mathrm{Na}^{+}$channel dependent action potentials with tetrodotoxin (TTX, $1 \mu \mathrm{M} ; i_{s}$ ), or from unitary synaptic events isolated from amplitude histograms collected in evoked transmission assays $\left(i_{e}\right)$.

Spontaneous sEPSCs and mEPSCs were examined off-line using Mini Analysis (6.0.3, Synaptsoft, Fort Lee, NJ) as previously described (Chen et al., 2001; Zhou et al., 2004). Only those events that arose abruptly and had peak amplitudes $>2.5 \mathrm{X}$ baseline RMS current noise (typically 1-2 pA) were selected for analysis. For each neuron, the timing and peak size of selected events were exported to Excel spreadsheets (11.5.5, Microsoft, Redmond, WA). Average sEPSC and mEPSC frequencies $\left(F_{s}\right.$ and $\left.f_{s}, \mathrm{~Hz}\right)$ were determined from the total number of events divided by the recording epoch duration (usually $2 \mathrm{~min}$ ) while sEPSC and mEPSC amplitudes were characterized from the average of individual amplitudes $\left(I_{s}\right.$ and $\left.i_{s}, \mathrm{pA}\right)$. To examine the distribution of EPSC frequencies and amplitudes, $F_{s}, f_{s}, I_{s}$, and $i_{s}$ values were compiled in cumulative histograms using Prism (4.0a, GraphPad, La Jolla, CA). Stimulusevoked EPSCs were identified using PulseFit (8.66, HEKA Instruments, Bellmore, NY) using the minimal stimulation and detection criteria described above, with the added requirement that they occur with fixed synaptic delay following fasicle stimulation. While the total delay was stable for any given trial, it varied between trials (typically from $\approx 2-10 \mathrm{~ms}$ ) likely because the distance between stimulating electrode and soma recording patch pipette ranged from $\approx 20$ $100 \mu \mathrm{m}$. For each recording, average eEPSC amplitudes $\left(I_{e}\right)$ were determined from the sum of all event amplitudes (including failures, $I_{e}=0$ ) divided by the total number of applied stimuli (usually 120). Unitary, mEPSC amplitudes $\left(i_{e}\right)$ were obtained by averaging event amplitudes within in the lowest component size of histograms assembled from all evoked events.

The plasma membrane $\mathrm{nAChR}$ population was stimulated by focally applying nicotine (Nic, $20 \mu \mathrm{M}$ in RS) via microperfusion (7-10 psi) to CG neuron somas held at $-70 \mathrm{mV}$. To ensure selective $\alpha 3 *$-nAChR activation, the cultures were pretreated with $50 \mathrm{nM} \alpha \mathrm{Bgt}$ to block $\alpha 7$ $\mathrm{nAChR}$ for $1 \mathrm{~h}$ as previously described (Nai et al., 2003; Zhou et al., 2004). The resulting peak current amplitudes and slow current decay were analyzed using Clampfit (pClamp 6.0 or 8.0, 
Axon Instruments, Burlingame, CA) as previously described (Nai et al., 2003; Zhou et al., 2004). Peak response amplitudes were normalized to neuron soma membrane capacitance (pA/ $\mathrm{pF})$, and values obtained from PACAP-treated $(100 \mathrm{nM}, 15 \mathrm{~min})$ and control neurons from the same cultures compared. Tetrodotoxin (TTX, $1 \mu \mathrm{M}$ ) was included in some experiments to test the effect of action potential blockade.

To assess changes in membrane excitability associated with PACAP treatment (Braas et al., 1998; DeHaven and Cuevas, 2004), patch pipettes were filled with $110 \mathrm{KMeSO}_{4}, 10 \mathrm{NaCl}, 5$ $\mathrm{MgCl}_{2}, 0.6$ EGTA, and 10 HEPES and the recording mode switched from voltage- to currentclamp after attaining the whole-cell configuration. Neurons displaying resting potential $\left(\mathrm{V}_{\text {rest }}\right)$ values $>-40 \mathrm{mV}$ or input resistance $\left(\mathrm{R}_{\text {in }}\right)$ values $<500 \mathrm{MO}$ were excluded. A family of $200 \mathrm{~ms}$ depolarizing current pulses (from 6 to $96 \mathrm{pA}$, in $6 \mathrm{pA}$ steps) was applied at $0.1 \mathrm{~Hz}$ to initiate action potentials. Action potential numbers and inter-spike intervals were computed and analyzed as a function of the applied current for PACAP-treated and control neurons.

\section{Drug treatments}

Unless otherwise stated, all reagents were added directly to established cultures maintained in MEM/eye. Acute treatments were for 15 min prior to recording on d 5 in culture. For washout studies, the media was replaced with MEM/eye at the end of treatment (for an additional 30 $\min$ to $48 \mathrm{~h}$ ). When signaling pathway inhibitors were tested, the neurons were pre-treated with the inhibitor for $15 \mathrm{~min}$ prior to exposure to PACAP (total treatment time of $30 \mathrm{~min}$ ). Treatment conditions included elevated $\mathrm{KCl}$ (addition of $45 \mathrm{mM} \mathrm{KCl}$ ), PACAP38 (1-300 nM; American Peptide, Inc., Sunnyvale, CA), forskolin $(10 \mu \mathrm{M})$, 8-Bromo-cyclic AMP (8Br-cAMP, $2 \mathrm{mM})$, SQ22536 $(10-100 \mu \mathrm{M})$, MDL12330A $(1-100 \mu \mathrm{M}), \mathrm{H} 89(10 \mu \mathrm{M}), \mathrm{U} 73122(0.1-1.0 \mu \mathrm{M}), \mathrm{Myr}-$ GRTGRRNAI-NH ${ }_{2}$ [PKI(14-22), $1 \mu \mathrm{M}$, Myristoylated Protein Kinase A Inhibitor Amide 1422, EMD Biosciences, San Diego, CA], L-Nitro-Arginine Methyl Ester (L-NAME, $100 \mu \mathrm{M}$ ), and sodium nitroprusside (SNP, $100 \mu \mathrm{M}$ ), either alone or in combinations, as described. Both maxadilan and Max.d.4 ( $\mathrm{PAC}_{1}$ agonist and antagonist, respectively) (Moro and Lerner, 1997; Moro et al., 1999) were generously provided by E. A. Lerner (Massachusetts General Hospital, Charlestown, MA). Unless otherwise specified, the pharmacological agents were purchased from Sigma-Aldrich (St. Louis, MO). The concentrations of activators and inhibitors used were based on previous studies either by this lab or others (Margiotta and Pardi, 1995; Csernus et al., 1999; Gadea et al., 1999; McIntosh et al., 1999; Pardi and Margiotta, 1999; Kimura, 2000; Pugh and Margiotta, 2000; Kanda and Watanabe, 2001; Mohamed et al., 2001; Wang et al., 2004; Zhou et al., 2004; Pugh and Margiotta, 2006).

\section{Statistics}

Parameter values (i.e. $F_{s}, f_{s}, I_{s}, I_{e}, i_{s}$, and $i_{e}$ ) are expressed as mean \pm SEM followed by the number of neurons from which values were obtained (n). Values from test conditions normalized to averages from control neurons in the same experiments are indicated by asterisks (e.g. $F_{S}^{*}, I_{s}^{*}$, etc). The statistical significance of differences in parameter values between control and PACAP treatment groups was determined using Student's unpaired, two-tailed $t$ test ( $t$-test, $p<0.05$ ) with Welch's correction for unequal variances used as necessary (Prism 4.0a). For comparisons of multiple treatment groups, significance was determined by one way ANOVA followed by Bonferroni's multiple comparison post-hoc test ( $p<0.05$; Prism 4.0a). Differences in parameter value cumulative distributions were assessed using the KolmogorovSmirnov (KS) test $(p<0.05$, available online at http://www.physics.csbsju.edu/stats/KS-test.html). 


\section{RESULTS}

\section{PACAP localization and release}

To test PACAP's potential for modulating nicotinic transmission, we first assessed its localization and voltage-dependent release in situ. In the developing CG, ciliary neurons receive 1:1 cholinergic input from accessory occulomotor neuron axons that terminate in a distinctive calyx enveloping most of the postsynaptic neuron surface (Hess, 1965; Landmesser and Pilar, 1972; Cantino and Mugnaini, 1975; Paysan et al., 2000). Consistent with their role as presynaptic terminals, calyces are strongly immunoreactive for the presynaptic markers, SV2 (Wilson Horch and Sargent, 1995) and Synapsin I. Further, Synapsin I and PACAP immunolabeling overlap considerably (Fig. $1 \mathrm{~A}-\mathrm{C} ; \mathrm{M}_{\mathrm{S}: \mathrm{P}} \approx \mathrm{M}_{\mathrm{P}: \mathrm{S}} \approx 0.70$ ), confirming that PACAP colocalizes with ACh in presynaptic terminals within the CG (Sumner et al., 2004). Previous studies have shown that neurotransmission from calyx to ciliary neuron reliably follows stimuli delivered at frequencies up to $50 \mathrm{~Hz}$ (Dryer and Chiappinelli, 1985) and that $16-20 \mathrm{~Hz}$ stimulation is sufficient to trigger PACAP release from splanchnic nerve terminals and intercardiac nerve fibers (Tornoe et al., 2000; Lamouche and Yamaguchi, 2001; Tompkins et al., 2007) where it is a co-transmitter with ACh (Hamelink et al., 2002; Tompkins et al., 2007). Consistent with activity-dependent PACAP release in the CG, sustained depolarization achieved by treating ciliary ganglia with RS containing $50 \mathrm{mM} \mathrm{KCl}(15 \mathrm{~min})$ abolished PACAP immunolabeling in calyces (Fig. 1D-F; $\mathrm{M}_{\mathrm{S}: \mathrm{P}} \approx 0.02$ ), leaving Synapsin I immunolabeling unaffected. Together with its ability to enhance nAChR function (Margiotta and Pardi, 1995; Pardi and Margiotta, 1999) and regulate catecholamine secretion (Hamelink et al., 2002), PACAP's localization in and activity-dependent release from cholinergic terminals prompted us to examine its functional role in modulating nicotinic neurotransmission.

\section{PACAP increases EPSC frequency and amplitude at nicotinic synapses on CG neurons}

CG neurons form an extensive synaptic network in culture, and by $3 \mathrm{~d}$ nearly all display sEPSCs (Margiotta and Berg, 1982; Chen et al., 2001). The vast majority of sEPSCs are mediated by $\alpha 3 *$-nAChRs since treating cultures with $\alpha \mathrm{CTx}$-MII to block $\alpha 3 *$-nAChRs (Chen et al., 2001) drastically reduced both sEPSC frequency and amplitude, while blocking $\alpha 7$-nAChRs with $\alpha$ Bgt had little effect (Chen et al., 2001). In the present studies, sEPSCs recorded from control cultures occurred at frequencies of $0.4-2.0 \mathrm{~Hz}$ and displayed peak amplitudes of 6 $100 \mathrm{pA}$ with overall mean values $\left(F_{S}\right.$ and $I_{S}$ ) of $1.3 \pm 0.1 \mathrm{~Hz}$ and $14.6 \pm 0.4 \mathrm{pA}$, respectively ( $\mathrm{n}=262$ neurons from 59 experiments). After $15 \mathrm{~min}$ application of $100 \mathrm{nM}$ PACAP, overall synaptic activity increased (Fig. 2A), as was reflected in $F_{s}$ and $I_{S}$ shifts to significantly larger mean values $(2.5 \pm 0.2 \mathrm{~Hz}$ and $18.6 \pm 0.6 \mathrm{pA}$, respectively; $\mathrm{n}=146)$ that were $3.8-\left(F_{s}{ }^{*}\right)$ and 1.4- $\left(I_{s}^{*}\right)$ times those obtained from sham-treated control neurons $(\mathrm{n}=154)$ tested in the same experiments (Fig. 2B, C). In time course studies, PACAP was seen to induce maximal increases in $F_{s}{ }^{*}$ and $I_{s}{ }^{*}$ within $5 \mathrm{~min}$, and its effects were sustained for up to $48 \mathrm{~h}$ following a single brief application (Fig. 2D, E). Thus PACAP rapidly increases both nicotinic sEPSC frequency and amplitude, and the synaptic modulation persists long after its removal.

\section{PACAP modulates nicotinic synapses via $\mathrm{PAC}_{1} \mathrm{Rs}$ and $\mathrm{AC} / \mathrm{PKA}-\mathrm{mediated}$ signal transduction}

PACAP activates two related classes of G-protein coupled receptors. VPAC receptors (VPACRs) have high affinity for both vasoactive intestinal peptide (VIP) and PACAP $\left(\mathrm{K}_{\mathrm{D}} \approx 1\right.$ $\mathrm{nM}$ ), while $\mathrm{PAC}_{1}$ Rs are PACAP-selective, having up to 1000 -fold lower affinity for VIP $\left(\mathrm{K}_{\mathrm{D}} \approx 1 \mu \mathrm{M}\right)$ (Vaudry et al., 2000). CG neurons express abundant $\mathrm{PAC}_{1}$ Rs. Previous competition studies indicated high-affinity PACAP binding on intact CG neurons, showing that peptide concentrations required to inhibit ${ }^{125}$-I-PACAP binding to half-maximum $\left(\mathrm{IC}_{50}\right)$ were 2000-fold lower for PACAP $(0.5 \mathrm{nM})$ than for VIP $(1 \mu \mathrm{M})$ (Margiotta and Pardi, 1995). $\mathrm{PAC}_{1}$ Rs signal via two canonical transduction cascades; one requiring PLC, inositol phosphate 
(IP) production and $\left[\mathrm{Ca}^{2+}\right]_{\text {in }}$ mobilization, and another requiring AC, cAMP production and subsequent PKA phosphorylation of downstream target proteins (Rawlings, 1994). In accord with the presence of signaling competent PAC $_{1}$ Rs (Vaudry et al., 2000) PACAP is $>10$-fold more potent than VIP in stimulating both cAMP production and IP turnover in CG neurons (Margiotta and Pardi, 1995; Pardi and Margiotta, 1999). While recent PCR experiments reveal transcripts encoding VPACR and $\mathrm{PAC}_{1} \mathrm{R}$ isoforms in CG RNA (Sumner, Pugh, and Margiotta, unpublished) only $\mathrm{PAC}_{1} \mathrm{Rs}$ that couple via $\mathrm{AC} / \mathrm{PKA}$-mediated transduction were required to enhance synaptic function. First, consistent with $\mathrm{PAC}_{1} \mathrm{R}$ involvement, PACAP potently and selectively enhanced synaptic function (Fig. 3A). Increasing PACAP concentrations (1-100 $\mathrm{nM}$ ) produced progressively larger values of sEPSC $F_{s}$ and $I_{S}$, and the nanomolar concentrations required to produce half-maximal stimulation $\left(\mathrm{EC}_{50} \approx 5 \mathrm{nM}\right.$ for both) were indicative of high potency. In accord with PACAP-selective actions, VIP failed to significantly augment either $F_{s}$ or $I_{s}$ when applied at $100 \mathrm{nM}$, a concentration at which PACAP produces maximal effects. $\underline{\text { Second, }}$ although PACAP potently activates PLC- as well as AC-dependent transduction in CG neurons (Margiotta and Pardi, 1995; Pardi and Margiotta, 1999) only ACdependent signaling was necessary to modulate nicotinic synaptic function (Fig. 3B, C). Specifically, the ability of PACAP to increase $\operatorname{sEPSC} F_{S}$ and $I_{s}$ was unaffected by inhibiting PLC with U-73122, previously shown to block PACAP stimulated IP turnover and $\left[\mathrm{Ca}^{2+}\right]_{\text {in }}$ mobilization in CG neurons (Pardi and Margiotta, 1999). Consistent with this finding, treatment with muscarine $(100 \mu \mathrm{M})$ which activates muscarinic acetylcholine receptors and induces IP turnover in the neurons (Rathouz et al., 1995) failed to enhance $\operatorname{sEPSC} F_{S}$ and $I_{s}$. By contrast, PACAP-induced increases in $F_{s}$ and $I_{s}$ were blocked by inhibiting AC with either MDL12330A (Guellan et al., 1977) or SQ-22356, a reagent previously shown to reduce cAMP production in CG neurons by $\approx 80 \%$ (Margiotta and Pardi, 1995). Consistent with AC-mediated transduction, the PACAP-induced enhancement of sEPSC $F_{s}$ and $I_{s}$ was mimicked by $8 \mathrm{Br}-$ cAMP, a membrane permeable cAMP analogue previously shown to enhance nAChR responses similar to that of PACAP (Margiotta et al., 1987; Margiotta and Pardi, 1995). Further supporting a requirement for AC- and cAMP-mediated signaling, PACAP's actions on sEPSCs were also blocked by PKI(14-22), a specific PKA inhibitor (Glass et al., 1989). This last finding indicates that, like PACAP-induced neuronal survival and nAChR upregulation (Pardi and Margiotta, 1999; Pugh and Margiotta, 2006), synaptic modulation is based on canonical AC signaling requiring cAMP accumulation and PKA phosphorylation of downstream targets. Taken together these relative-potency and effector-dependence experiments indicate that PACAP engages $\mathrm{PAC}_{1}$ Rs that efficiently couple to AC/PKA-mediated transduction to modulate synaptic function.

\section{PACAP does not increase the excitability of CG neurons}

We considered three possible mechanisms whereby PACAP/PAC $\mathrm{P}_{1} \mathrm{R}$ signaling could enhance $\operatorname{sEPSC} F_{s}$ and $I_{s}$. The first was by increasing neuronal excitability, as was found in previous studies where PACAP markedly increased action potential repetitive firing in cardiac ganglion neurons by $\approx 5$-fold, concomitant with a sustained $(\approx 5-7 \mathrm{mV})$ depolarization (Braas et al., 1998; DeHaven and Cuevas, 2004; Tompkins et al., 2007). PACAP (100 nM) did depolarize CG neurons since resting potentials recorded in current-clamp mode after 5 to $15 \mathrm{~min}$ treatments were $-48.1 \pm 0.8 \mathrm{mV}(\mathrm{n}=8)$ compared with $-53.9 \pm 0.4 \mathrm{mV}(\mathrm{n}=8)$ for shamtreated neurons from the same cultures tested in parallel $(p<0.05, t$-test). The latter values were indistinguishable from the $-56.0 \pm 1.0 \mathrm{mV}$ mean resting potentials $(p>0.05, \mathrm{n}=80, t$ test) previously obtained from CG neurons in culture using sharp electrodes (Margiotta and Berg, 1982). Unlike cardiac ganglion neurons, however, PACAP markedly reduced the excitability of CG neurons. As depicted in Fig. 4, control CG neurons fired low-frequency action potentials when sufficiently depolarized such that the number of spikes increased linearly from 1.4 at $6 \mathrm{pA}$ to 4.5 at $96 \mathrm{pA}$ (slope $=0.039 \mathrm{pA}^{-1}$ ). After PACAP treatment, however, repetitive firing was virtually abolished with only 1.0-1.8 spikes elicited over the 
same stimulus range (slope $\approx 0.001 \mathrm{pA}^{-1}$ ). In addition, the membrane potential threshold required to produce an action potential was more depolarized in the PACAP-treated neurons $(-43.9 \pm 1.1 \mathrm{mV}, \mathrm{n}=8)$ relative to that for controls $(-49.0 \pm 0.3 \mathrm{mV}, \mathrm{n}=8, p<0.05)$ and the net voltage from baseline to action potential peak $(\Delta \mathrm{V})$ was significantly decreased after PACAP treatment (from $\Delta \mathrm{V}=79.2 \pm 3.1 \mathrm{mV}$ to $63.2 \pm 3.5 \mathrm{mV}$, for control and PACAP-treated neurons, $\mathrm{n}=7$ and 5 cells, respectively). Lastly, in cases where PACAP treated neurons displayed $>1$ action potential, the increase in spike frequency as a function of stimulus strength was indistinguishable from that of control neurons (slope $\approx 0.2 \mathrm{~Hz} / \mathrm{pA}$ for both, $\mathrm{p}>0.2, F$-test; data not shown). Mechanisms underlying these PACAP-induced changes in membrane properties were not examined further. Nevertheless, the higher action potential threshold and depressed action potential firing are inconsistent with what would be expected if PACAP enhanced synaptic function by increasing the excitability of CG neurons.

\section{PACAP does not alter postsynaptic AChRs}

The remaining candidate mechanisms for the enhanced synaptic function involve PACAP influencing either postsynaptic nAChRs or presynaptic ACh release and were addressed by analyzing quantal components of spontaneous and evoked EPSCs. Since PACAP increases sEPSC amplitude ( $I_{s}$, Fig. 2) and previous rapid agonist application studies revealed that it rapidly increases $\alpha 3 *-n A C h R$ responses from acutely dissociated E14 CG neuron somas (Margiotta and Pardi, 1995;Pardi and Margiotta, 1999) tests for a postsynaptic mechanism were conducted first. mEPSCs are considered indicative of nAChRs activated at postsynaptic clusters by ACh released from single vesicles from adjacent presynaptic terminals (Lin and Bennett, 1994;Bekkers and Stevens, 1995;Chen et al., 2001;Conroy et al., 2007). If PACAP enhanced transmission by a mechanism involving global upregulation of all $\alpha 3^{*}$-nAChRs on the neuron soma, including those at postsynaptic sites, it would be expected to increase average mEPSC amplitude ( $i_{\mathrm{s}}$, quantal size) since we previously found that the vast majority of sEPSCs are sensitive to blockade by $\alpha \mathrm{CTx}$-MII and hence mediated by $\alpha 3 *$-nAChRs (Chen et al., 2001; Nai et al., 2003). Quantal, nAChR-mediated mEPSCs are detectable in CG neurons following action potential blockade with TTX $(1 \mu \mathrm{M})$ and are smaller and occur at lower frequencies than impulse-dependent sEPSCs both in situ and in culture (Scott and Bennett, 1993a;Scott and Bennett, 1993b;Lin and Bennett, 1994;Ullian et al., 1997;Chen et al., 2001). In the present experiments, criterion mEPSCs (i.e. events with peak amplitudes at least $2.5 \mathrm{X}$ baseline RMS current noise) were routinely observed after TTX treatment (Fig. 5). The mEPSCs were quite uniform in size, since the vast majority had amplitudes that fell within one standard deviation of the overall mean value $\left(i_{s}=7.2 \pm 0.3 \mathrm{pA} ; \mathrm{n}=37\right)$ both within and across a total of nine separate cultures (Fig. 5A and B). In addition, and as expected for quantal events, mEPSC frequency and amplitude were independent of $\left[\mathrm{Ca}^{2+}\right]_{\text {out }}$ ranging from 0 to $5 \mathrm{mM}$ (data not shown). Moreover, treating cultures with $\alpha B g t(50 \mathrm{nM}, 1 \mathrm{~h}$ ) to block $\alpha 7$-nAChRs, the only other nAChR subtype expressed by the neurons (Nai et al., 2003) failed to alter either mEPSC frequency or amplitude, respectively $(0.59 \pm 0.14 \mathrm{~Hz}$ and $7.6 \pm 0.5 \mathrm{pA}, \mathrm{n}=4)$, relative to untreated controls $(0.70 \pm 0.47 \mathrm{~Hz}$ and $6.5 \pm 1.4 \mathrm{pA}, \mathrm{n}=3)$ from the same experiments $(\mathrm{p}>$ 0.5 for both, $t$-test). These and previous pharmacological tests with $\alpha \mathrm{CTx}$-MII indicate that the vast majority of detectable mEPSCs are mediated by the $\alpha 3 *$-nAChR subtype. To our surprise, mEPSCs acquired from PACAP/TTX-treated neurons were very similar to those acquired from neurons treated with TTX alone and tested in the same four experiments (Fig. 5B-D, Table 1). A shift to slightly higher maximal mEPSC frequencies was evident in cumulative distributions compiled for PACAP/TTX treated neurons relative to accompanying TTX-controls, but the mean $f_{s}$ value for these treated neurons was not measurably different from that for TTXcontrols. Moreover, mEPSC amplitudes were not detectably influenced by PACAP since neither the cumulative distributions nor the mean $i_{s}$ values for PACAP/TTX-treated and TTXcontrol neurons differed significantly. 
We first examined whether the failure of PACAP to influence mEPSC amplitude resulted from a paradoxical failure of $\mathrm{PACAP} / \mathrm{PAC}_{1} \mathrm{R}$ signaling to influence synaptic function. When tested in these same experiments, however, PACAP treated, TTX-naïve neurons $(\mathrm{n}=16)$ displayed $F_{s}$ and $I_{s}$ values that were $4.0 \pm 0.7$ times and $1.8 \pm 0.2$ times those of corresponding values obtained from TTX-naïve neurons $(\mathrm{n}=22)$ tested in parallel $\left(p<0.05\right.$ for both $F_{s}$ and $I_{s}, t$ test). We next addressed the possibility that the recording setup was insufficiently sensitive to resolve $25-75 \%$ increases in quantal size necessary to account for the increase in $I_{s}$. This possibility was also rejected because after changing the holding potential from -70 to $-90 \mathrm{mV}$ a predictable $30 \%$ increase in mEPSC amplitude was easily resolved (data not shown). Lastly, we considered that $\alpha 3^{*}$-nAChR upregulation by PACAP may not occur in culture, particularly after treatment with TTX. This possibility was also eliminated since peak whole-cell $\alpha 3^{*}$ $\mathrm{nAChR}$ current amplitudes induced by rapid nicotine microperfusion in PACAP treated neurons were $\approx 2.4$ times larger than those of sham-treated controls, and a similar enhancement was observed when incubations and tests were conducted in the presence of TTX (Fig. 5E). These experiments indicate that while PACAP/PAC $\mathrm{P}_{1} \mathrm{R}$ signaling rapidly increases $\alpha 3 *_{\text {- }}$ nAChR-mediated currents in CG neurons, it fails to influence quantal size. Thus postsynaptic $\alpha 3 *-n A C h R s$, responsible for the vast majority of sEPSCs and mEPSCs seen previously and here appear refractory to further regulation by exogenous PACAP.

\section{PACAP enhances synaptic activity by increasing mean quantal content}

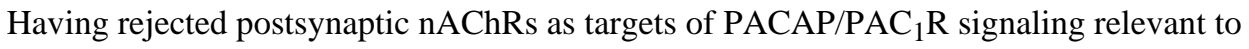
synaptic modulation, we addressed the possibility that PACAP alters presynaptic function. To do so, altered $\mathrm{ACh}$ release was evaluated by measuring mean quantal content $(m)$ presumed to represent the average number of presynaptic vesicles released by a single impulse (Johnston and $\mathrm{Wu}, 1995)$. Initial determinations of $m$ were based on sEPSCs and obtained from average sEPSC and mEPSC amplitudes $\left(I_{s}\right.$ and $i_{s}$ ) using the empirical relation $m_{s}=I_{s} / i_{\mathrm{S}}$ (del Castillo and Katz, 1954; Johnston and $\mathrm{Wu}, 1995)$. When calculated using $I_{s}$ and $i_{\mathrm{s}}$ values obtained from separate neurons from the same cultures, $m_{s}(2.0 \pm 0.3, \mathrm{n}=19$, Table 1$)$ was indistinguishable from that calculated using $I_{S}$ and $i_{\mathrm{S}}$ values compiled from individual neurons before and after TTX treatment $\left(m_{s}=1.6 \pm 0.1, \mathrm{n}=3 ; p>0.5, t\right.$-test $)$. Using the former method we calculated that PACAP treatment increased $m_{s}$ to $\approx 1.6$ times that of sham treated controls from the same experiments $(2.9 \pm 0.3, \mathrm{n}=16 ; p<0.01$, Table 1$)$. While this finding suggests that PACAP enhances nicotinic synaptic transmission by influencing presynaptic function, sEPSC-based determinations of quantal content are potentially limited by two opposing factors. First, impulse independent mEPSCs will be included, skewing the distribution of sEPSC amplitudes to lower values and reducing $m$. Second, transmission failures (where $I_{s}=0$ ) will be unresolved and thus not included in the overall averages, as would be appropriate (del Castillo and Katz, 1954; Johnston and $\mathrm{Wu}, 1995)$, skewing overall sEPSC amplitudes to higher values and increasing $m$.

To circumvent these potential problems, we devised a way to evoke transmission between preand postsynaptic neuron pairs. In doing so, it was presumed that any given neuron would most likely receive direct presynaptic input from axons traveling in neurite fasicles that converge upon its soma. Indeed, when convergent fasicles were stimulated, short-latency currents indicative of synaptic transmission evoked by single axon impulses were seen in $\approx 90 \%$ of target somas ( $\mathrm{n}=58$ fasicles, 25 neurons), whereas stimulation of non-convergent fasicles failed to evoke such currents (Fig. 6A). The currents induced by convergent fasicle stimulation met criteria expected for impulse-dependent, nAChR-mediated evoked EPSCs (eEPSCs). They arose with fixed delay, their brief onset and slower decay kinetics resembled those of $\alpha 3 *_{\text {- }}$ nAChR-mediated sEPSCs (Fig. 6A,B), their peak amplitudes were increased by hyperpolarization and reduced by depolarization, and they were reversibly abolished by blocking $\mathrm{Na}^{+}$channels with TTX or nAChRs with $d$-tubocurarine (data not shown). 
The ability to reliably evoke transmission between CG neuron pairs allowed us to test two established methods for evaluating quantal components of transmission at individual synapses (Martin and Pilar, 1964; Johnston and $\mathrm{Wu}, 1995)$. The first is empirical where $m_{e}$ is based on the ratio of average evoked response amplitudes $\left(I_{e}\right.$, including failures where $\left.I_{e}=0\right)$ relative to average unitary mEPSC amplitudes $\left(i_{e}\right)$ collected from the same neurons $\left(m_{e}=I_{e} / i_{e}\right)$. Importantly, $i_{e}$ values differed from those of spontaneous event amplitudes acquired in TTX $\left(i_{s}\right)$ by $<15 \%$, and PACAP treatment similarly failed to alter $i_{e}$ (Table 1$)$. The second evoked method arises from the Poisson failure prediction which assumes low release probability $(p)$ and derives $m$ based on the total number of delivered stimuli $\left(N_{T}\right)$ relative to the number failures $\left(N_{O}\right)$, and is given by $m_{f}=\ln \left(N_{T} / N_{O}\right)$. In control experiments, values of $m$ derived from the failure method were $\approx 40 \%$ of those obtained empirically, possibly because $p$ in these studies (unknown) is not optimally suited to fulfill the Poisson approximation. Nevertheless, results obtained using either method were consistent with those obtained by analyzing sEPSCs, revealing in both cases, that PACAP selectively increases quantal content (Fig. 6, Table 1). While quantal content varied considerably across cultures such that overall values of $m_{e}$ and $m_{f}$ were only nominally larger for PACAP-treated neurons, PACAP did significantly increase quantal content within cultures. Thus $m_{e}{ }^{*}$ and $m_{f}^{*}$ values were, respectively, 1.8- and 2.7-times higher for PACAP-treated neurons relative to control neurons evaluated in the same cultures ( $p<0.05$ for both; Table 1). Similarly, daily plots of $m_{e}$ and $m_{f}$ for PACAP treated versus control neurons reveal linear relationships having non-zero slopes for both that predicted 2.2and 4.2-fold increases, respectively, in quantal content associated with PACAP treatment (Fig. $6 \mathrm{C}, \mathrm{D})$. The increases in quantal content occurred without detectable changes in mEPSC amplitudes (Table 1) indicating again that quantal size is unaffected by PACAP regulation. Based on these findings, it is concluded that PACAP rapidly enhances nicotinic transmission parameters (sEPSC $F_{S}$ and $I_{s}$ ) by selectively altering presynaptic function, as indicated by its ability using three assays to increase mean quantal content independent of quantal size.

\section{Nitric oxide production is required for PACAP-mediated synaptic effects}

Increased quantal content was previously found to accompany long-term potentiation at nicotinic synapses on CG neurons in situ, and both were linked to elevated NO production (Lin and Bennett, 1994). Interestingly, PACAP stimulates production of neuronal nitric oxide synthase (nNOS), the enzyme critical for NO production (Bredt and Snyder, 1990) in pituitary gonadotrophs and dorsal root ganglion neurons and does so in a cAMP-, PKA-, and calmodulindependent manner (Bredt and Snyder, 1990; Bredt et al., 1992; Garrel et al., 2002). We therefore considered the hypothesis that $\mathrm{PACAP} / \mathrm{PAC}_{1} \mathrm{R}$ signaling enhances nicotinic synaptic function by activating NOS and subsequently increasing NO production (Fig. 7). The first test was to determine a NOS requirement by pre-treating cultures with the NOS inhibitor L-NAME and assessing subsequent PACAP-induced modulation of synaptic function. L-NAME (100 $\mu \mathrm{M}, 15 \mathrm{~min}$ ) applied alone had no effect on basal synaptic transmission, but when PACAP was applied after L-NAME treatment, it failed to increase $\operatorname{sEPSC} F_{s}$ (Fig. 7A) or $I_{s}$ (data not shown). Thus nNOS activity appears required for PACAP to enhance transmission at neuronal nicotinic synapses. The second test was to determine if exogenous NO mimics the actions and mechanism of PACAP induced synaptic modulation, and this also seems to be the case. Treating cultures with the NO donor, SNP $(100 \mu \mathrm{M}, 15 \mathrm{~min})$, rapidly increased sEPSC $F_{S}$ to levels that were indistinguishable from those produced by PACAP (Fig. 7A). Moreover, as with PACAP, the SNP-induced elevation of $F_{S}$ was accompanied by increased quantal content. The latter conclusion was reached because SNP treatment shifted the distribution of sEPSC amplitudes to significantly larger values (Fig. 7B) without changing the distribution of mEPSC amplitudes acquired from neurons in the same three cultures (Fig. 7C) thereby predicting an increase in $m_{S}\left(=I_{S} / i_{S}\right)$. While these results do not identify obligatory signaling steps between PACAP/PAC 1 , NOS/NO stimulation, and the relevant synaptic targets, they do indicate that 
$\mathrm{PACAP} / \mathrm{PAC}_{1}$ signaling alters nicotinic synaptic function by mechanisms that depend on NOS activation and subsequent release of NO.

\section{DISCUSSION}

The ability of PACAP to regulate nAChR function (Margiotta and Pardi, 1995; Pardi and Margiotta, 1999; Liu et al., 2000) and its localization to ACh-containing presynaptic terminals throughout the nervous system (Holgert et al., 1996; Braas et al., 1998; Calupca et al., 2000; Tornoe et al., 2000; Locknar et al., 2002; Richardson et al., 2003; Drescher et al., 2006) suggested that PACAP signaling would influence nAChR-mediated synaptic transmission. The present findings support this view, demonstrating that PACAP immunoreactivity disappears from cholinergic terminals on $\mathrm{CG}$ neurons following $\mathrm{KCl}$ depolarization and that PACAP activates $\mathrm{PAC}_{1} \mathrm{Rs}$ and $\mathrm{AC} / \mathrm{PKA}$-dependent signaling to rapidly and persistently enhance nAChR-mediated synaptic transmission in CG cultures. Surprisingly, however, PACAP regulated synaptic function without influencing postsynaptic nAChRs (quantal size), but instead did so by increasing ACh release from presynaptic terminals (quantal content). Moreover, this presynaptic influence was dependent on NOS and subsequent mobilization of the gaseous messenger, NO. Taken together, the findings reveal that canonical $\mathrm{PAC}_{1} \mathrm{R}$ - and NOS-dependent signaling mechanisms converge to regulate presynaptic function.

Levels of PACAP increase in the CG throughout embryonic development from E8 to E20 (Pugh and Margiotta, 2006), and cholinergic presynaptic terminal calyces that innervate ciliary neurons display intense PACAP immunoreactivity by E19 (Fig. 1 and Sumner et al., 2004). The subcellular distribution of PACAP within calyces is unknown, however, PACAP immunoreactivity has been localized to large dense core vesicles ( $80-120 \mathrm{~nm}$ diameter) typical for neuropeptides in presynaptic terminals providing input to hypothalamic paraventricular and spinal cord intermediolateral nucleus neurons (Chiba et al., 1996; Légrádi et al., 1997). Two major size classes of dense core vesicles, $(\approx 85$ and $\approx 120 \mathrm{~nm})$ have been identified in CG presynaptic terminals, with enkephalin and substance $\mathrm{P}$ both localizing to the smaller subclass (Erichsen et al., 1982), and from which enkephalin release has been demonstrated (Meriney et al., 1991). The specific vesicle class that contains PACAP and the impulse frequencies that best induce its release remain to be determined. In other autonomic preparations, however, depolarizing pulses delivered at $\approx 20 \mathrm{~Hz}$ release endogenous PACAP, and do so by a $\mathrm{Ca}^{2+}$ dependent mechanism consistent with vesicular secretion (Katsoulis et al., 1996; Tornoe et al., 2000; Lamouche and Yamaguchi, 2001; Tompkins et al., 2007). Since orthodromic transmission to ciliary neurons occurs reliably at stimulus frequencies of $25-100 \mathrm{~Hz}$ (Dryer and Chiappinelli, 1985; Chang and Berg, 1999) and sustained depolarization depletes PACAP from calyces (Fig. 1), it seems likely that these presynaptic terminals would release both ACh and PACAP at physiological firing frequencies.

PACAP application engages $\mathrm{PAC}_{1}$ Rs on CG neurons, activating canonical AC- and PKAdependent signal cascades that rapidly and persistently increase the frequency and amplitude of sESPCs in culture (Figs. 2,3). We initially considered two plausible mechanisms to explain PACAP's actions on nicotinic synapses. The first was that PACAP might increase the excitability of CG neurons within the culture network, as it does for other autonomic neurons (Braas et al., 1998;DeHaven and Cuevas, 2004;Tompkins et al., 2007). This mechanism was excluded, however, because PACAP slightly raised action potential threshold and blocked repetitive firing (Fig. 4). While neither effect has been investigated further, the higher threshold is consistent with the sustained PACAP-induced depolarization increasing resting $\mathrm{Na}^{+}$channel inactivation (Hodgkin and Huxley, 1952). In addition, the blockade of repetitive firing may result from the ability of PACAP to elevate intracellular $\mathrm{Ca}^{2+}$ in CG neurons (Pardi and Margiotta, 1999; Woo and Margiotta, 2007), and thereby stimulate $\mathrm{Ca}^{2+}$-activated smallconductance $\mathrm{K}^{+}$channels (Power and Sah, 2008) which are known to reduce repetitive firing 
(Pedarzani and Stocker, 2008;Louise Faber, 2009). Alternatively, PACAP might reduce transient Atype potassium (KA) channel currents which can support repetitive firing (Kim et al., 2005; Sonner and Stern, 2007) particularly at the modest firing frequencies seen here (Connor and Stevens, 1971). Consistent with this idea, PACAP reduced both KA channel currents and subunit expression in olfactory neurons (Han and Lucero, 2005,2006).

The second possibility was that PACAP might increase $\alpha 3^{*}$-nAChR mediated mEPSC amplitudes (i.e. quantal size). This seemed likely because we previously found that PACAP acting via $\mathrm{PAC}_{1} \mathrm{Rs}, \mathrm{AC}$, and PKA rapidly increased whole cell-currents mediated by somatic $\alpha 3^{*}$-nAChRs (Pardi and Margiotta, 1999) and because $\alpha 3^{*}$-nAChRs underlie the vast majority of sEPSCs and mEPSCs detected here (Ullian et al., 1997; Chen et al., 2001). Surprisingly, however, PACAP failed to influence quantal size (Fig. 5, Table 1), and control experiments indicated this result did not arise from insufficient resolution, the cell culture environment, or TTX treatment. Thus $\alpha 3 *$-nAChRs localized to the postsynaptic membrane, unlike those distributed elsewhere on the soma (Margiotta and Pardi, 1995; Pardi and Margiotta, 1999), appear refractory to regulatory influence by exogenous PACAP. Ultrastructural and autoradiographic studies, using toxin $(N$-Bgt) and antibody (mAb35) probes that recognize $\alpha 3 *$-nAChRs, do distinguish $\alpha 3 *$-nAChR populations on CG neurons based on their relative abundance and presence at postsynaptic versus extrasynaptic (i.e. non- and peri-synaptic) sites (Jacob et al., 1986; Loring and Zigmond, 1987; Shoop et al., 2001). In 5 d CG cultures, surface binding studies with these same reagents reveal $\approx 10^{5} \alpha 3^{*}$-nAChRs per neuron (Halvorsen and Berg, 1987), and by analyzing mAb35 and SV2 labeled confocal images, we estimate that $30 \%$ of mAb35 surface labeling is somatic and of this only $15 \%$ (corresponding to $\approx 4,500 \alpha 3 *_{\text {- }}$ $\mathrm{nAChRs}$ ) is localized in postsynaptic clusters (i.e. immediately adjacent to SV2 labeling; J.F. Margiotta and S.J. Jayakar, unpublished). Several features may distinguish low-abundance, postsynaptic $\alpha 3 *$-nAChRs from those distributed extrasynaptically. One is subunit stoichiometry since $80 \%$ of $\alpha 3 *$-nAChRs are assembled from $\alpha 3$, $\alpha 5$, and $\beta 4 \mathrm{nAChR}$ subunits while $20 \%$ also contain $\beta 2$ subunits (Vernallis et al., 1993; Conroy and Berg, 1995) raising the possibility that different proportions of the two $\alpha 3 *$-nAChR subtypes are present at postversus extrasynaptic sites (see also(Sargent, 2009). A second distinguishing feature may be the degree to which post- and extra-synaptic $\alpha 3 *$-nAChRs associate with cytoplasmic scaffolding and/or anchoring proteins. $\alpha 7$-nAChRs, for example, are linked to the F-actin scaffold, and disruption of this linkage dramatically alters their function (Liu and Berg, 1999). In addition, $\alpha 3 *^{*}$ and $\alpha 7$-nAChRs on CG neurons associate with different PDZ proteins but it is not known if the $\alpha 3 *-n A C h R$ association with PSD-95 is obligatory or if it can also occur without (or with different) scaffolding proteins. In the CNS, association of synaptic NMDA receptors with PSD-95 provides a platform ensuring proximity to intracellular effectors and signaling cascades critical for synaptic function (Kennedy et al., 2005); the same may be true for nAChRs. We recently found that A-kinase anchoring proteins (AKAPs) are required for $\mathrm{PACAP} / \mathrm{PAC}_{1} \mathrm{R}$ PKA-dependent signaling to regulate synaptic function but not to enhance $\alpha 3^{*}$-nAChR currents (Jayakar et al., 2009). Lastly, endogenous PACAP present in CG calyces (Fig. 1) and in the cultures (Sumner and Margiotta, 2008) may act locally to potentiate postsynaptic $\alpha 3 *$-nAChRs such that exogenous PACAP has no further potentiating effect on them. These considerations suggest that differences in subunit composition, association with scaffold and AKAP protein platforms, and prior history can influence the ways synaptic and extrasynaptic $\alpha 3^{*}$-nAChRs respond to PACAP/PAC 1 R-triggered intracellular signaling.

Since PACAP/PAC $\mathrm{P}_{1} \mathrm{R}$ signaling failed to influence quantal size, we sought to determine whether it enhanced presynaptic ACh release by increasing mean quantal content, $m$. Consistent with this idea was the initial observation that sEPSC amplitudes increased after PACAP treatment while mEPSC amplitudes remained unchanged, predicting a $>50 \%$ increase in $m_{s}$ (Table 1). Subsequent quantitative transmission studies, conducted by stimulating presynaptic axon fasicles to evoke EPSCs in target CG neuron somas, confirmed the 
involvement of a presynaptic mechanism (Fig. 6). In these studies, calculations based on the ratio of mean eEPSC to mEPSC amplitudes $\left(m_{e}=I_{e} i_{e}\right)$ and on transmission failures $\left[m_{f}=l n\right.$ $\left(N_{T} / N_{0}\right)$ ] predicted different quantal content values, possibly because the low $p$ requirement of the Poisson model does not strictly apply. Nevertheless, PACAP significantly increased $m$ using both methods of determination (Fig. 6, Table 1). It is unlikely that this conclusion results from misidentifying impulse failures as transmission failures. First, introducing impulse failures in a synaptic model reduced both $m_{e}$ and $m_{f}$, and did so to similar degrees (J. Margiotta, unpublished). Second, since PACAP increases impulse threshold and lowers excitability (Fig. 4) it would be expected to increase impulse failures, biasing $m_{e}$ and $m_{f}$ to lower values. Such reductions in $m$ are opposite to what is observed. The applicability of employing the EPSC amplitude ratio and Poisson failure methods in the evoked studies is supported by the observation that while $m_{e}$ and $m_{f}$ varied between experiments, they were linearly related in both control and PACAP-treated neuron pairs. Further, plotting $m_{e}$ versus $m_{f}$ obtained in different experiments resulted in slopes that were indistinguishable between control and PACAP-treated neurons ( 2.5 versus 1.8 , respectively, $\mathrm{p}>0.05$, data not shown). This latter finding indicates that PACAP alters quantal content without globally perturbing synaptic function. We hypothesize that the larger sEPSC amplitudes resulting from elevated quantal content would amplify the effects of PACAP throughout the culture network, bringing each interconnected neuron closer to impulse threshold and thereby causing even greater increases in $F_{s}$, as is observed.

In exploring how $\mathrm{PACAP} / \mathrm{PAC}_{1} \mathrm{R}$ signaling could enhance presynaptic transmitter release, we uncovered an obligatory connection to NOS and subsequent release of the gaseous messenger, $\mathrm{NO}$ (Fig 7). Consistent with our findings, PACAP stimulates NOS and increases NO production in spinal cord nerve endings of dorsal root ganglion neurons (Mabuchi et al., 2004) by a mechanism likely involving NOS translocation to the plasma membrane (Ohnishi et al., 2008). In the CG system subcellular sites where $\mathrm{PAC}_{1} \mathrm{Rs}$ might couple with NOS and thereby increase NO production are unknown. Since CG neuron cultures express both $\mathrm{PAC}_{1} \mathrm{Rs}$ (this study and (Pugh and Margiotta, 2006) and NOS transcripts (Sumner and Margiotta, 2008),

$\mathrm{PAC}_{1}$ Rs and NOS co-localized either in CG neuron somas or presynaptic terminals could, in principle, account for the effects observed here. Thus $\mathrm{PAC}_{1} \mathrm{R}$-mediated NOS activation would induce $\mathrm{NO}$ production at either site, allowing it to influence ACh release from presynaptic terminals by retrograde or direct mechanisms, respectively, as previously demonstrated in intracellular recordings from CG neurons conducted in situ (Scott and Bennett, 1993a;Scott and Bennett, 1993b;Lin and Bennett, 1994). In the ciliary ganglion, NOS is expressed in both neurons and presynaptic terminals (Nichol et al., 1995;Cuthbertson et al., 1999) and PAC $_{1}$ Rs are abundant on freshly-dissociated CG neuron somas (Margiotta and Pardi, 1995; Pardi and Margiotta, 1999; Woo and Margiotta, 2007;Sumner and Margiotta, 2008). Since PAC P R transcripts are absent from neurons providing presynaptic input to the CG (Peeters et al., 2000) and Peeters, personal communication), however, the locus of NOS and $P_{A C} R$ interaction in situ may be confined to CG neuron somas. Consistent with this constraint and with a requirement for AC/PKA-dependent processes to enhance synaptic function (Fig. 3), $\mathrm{PAC}_{1} \mathrm{R}$ transduction via $\mathrm{AC}$ and PKA increases CG neuron somatic cAMP and, by the resulting enhanced $\alpha 3 *^{*}$ and $\alpha 7$-nAChR-mediated currents (Margiotta and Pardi, 1995;Pardi and Margiotta, 1999), elevates somatic $\mathrm{Ca}^{2+}$ (Verino et al., 1992;Bertrand et al., 1993; Séguéla et al., 1993). Both cAMP and $\mathrm{Ca}^{2+}$ are known to stimulate NOS (Oess et al., 2006;Ohnishi et al., 2008) an action that would increase somatic NO output and thus be expected to influence presynaptic $\mathrm{ACh}$ release in a retrograde fashion. Interestingly, a retrograde signal regulates ACh release at nicotinic synapses in mouse sympathetic ganglia where a disruption in the $\alpha 3$ $\mathrm{nAChR}$ subunit gene abolishes synaptic transmission and $\alpha 3-\mathrm{nAChR}$ mediated currents (Rassadi et al., 2005). In that case, the loss of postsynaptic activity impairs presynaptic ACh release by reducing high-affinity choline transporter (CHT) function and expression (Krishnaswamy and Cooper, 2009). Increased CHT expression could similarly underlie the 
enhanced synaptic function induced by PACAP in CG neuron cultures that persists for days after exposures of only minutes. Indeed, in a recent gene array study, brief PACAP exposure (15 min, followed by $6 \mathrm{~h}$ incubation in normal culture medium) upregulated CHT transcripts to levels that were 2.1 times those of sham-treated controls (Sumner and Margiotta, 2008). Interestingly, gene transcripts encoding choline acetyltransferase and synaptotagmin IV were similarly increased after brief PACAP exposure (Sumner and Margiotta, 2008). Thus PACAP rapidly upregulates the expression of transcripts encoding presynaptic proteins involved not only in choline transport, but also in ACh synthesis and release, all of which could sustain enhanced synaptic function consistent with the core findings reported here.

The actions of PACAP/PAC $\mathrm{R}_{1}$ signaling on synapses are similar to nicotinic long-term potentiation (LTP) previously described in the intact CG (Scott and Bennett, 1993b) because both have a presynaptic locus and share NOS/NO dependence (Figs. 5-7). As mentioned above, PACAP is released by delivering presynaptic stimuli at $\approx 20 \mathrm{~Hz}$ in other autonomic preparations (Tornoe et al., 2000; Lamouche and Yamaguchi, 2001; Tompkins et al., 2007). Since these frequencies are similar to the $30 \mathrm{~Hz}$ necessary to induce LTP in the CG (Scott and Bennett, 1993b) and are expected to release both ACh and PACAP, the subsequent PAC $\mathrm{C}_{1}$-generated signaling demonstrated here may be required for LTP. The long-lasting effects of even brief PACAP exposure (Fig. 2 and (Sumner and Margiotta, 2008) further suggest that its release need not be sustained for the peptide to exert long term effects on neurotransmission and other critical processes. Thus PACAP's broad expression, colocalization with ACh, and its rapidonset yet persistent effects on nAChR-mediated transmission seen here, suggest PACAP will emerge as a critical modulator of nicotinic synapses throughout the nervous system.

\section{Acknowledgments}

Support was provided by NIH grants K01-DA15553 to PCP and R01-DA015536 and R21-DA022280 to JFM. We thank Drs. Gail Adams and Adriane Sumner, and Ms. Gowri Hegade for technical assistance, and Drs. Marthe Howard, Peter Sargent and Ellis Cooper for helpful comments.

\section{References}

Bekkers JM, Stevens CF. Quantal analysis of EPSCs recorded from small numbers of synapses in hippocampal cultures. J Neurophysiol 1995;73:1145-1156. [PubMed: 7608761]

Bertrand D, Galzi J, Devillers-Thiéry A, Bertrand S, Changeux J-P. Mutations at two distinct sites within the channel domain M2 alter calcium permeability of neuronal $\alpha 7$ nicotinic receptor. Proc Natl Acad Sci U S A 1993;90:6971-6975. [PubMed: 7688468]

Braas K, May V, Harakall S, Hardwick J, Parsons R. Pituitary adenylate cyclase-activating polypeptide expression and modulation of neuronal excitability in guinea pig cardiac ganglia. J Neurosci 1998;18:9766-9779. [PubMed: 9822736]

Braas KM, Schutz KC, Bond JP, Vizzard MA, Girard BM, May V. Microarray analyses of pituitary adenylate cyclase activating polypeptide (PACAP)-regulated gene targets in sympathetic neurons. Peptides 2007;28:1856-1870. [PubMed: 17512639]

Bredt DS, Snyder SH. Isolation of nitric oxide synthetase, a calmodulin-requiring enzyme. Proc Natl Acad Sci USA 1990;87:682-685. [PubMed: 1689048]

Bredt DS, Ferris CD, Snyder SH. Nitric oxide synthase regulatory sites. Phosphorylation by cyclic AMPdependent protein kinase, protein kinase $\mathrm{C}$, and calcium/calmodulin protein kinase; identification of flavin and calmodulin binding sites. J Biol Chem 1992;267:10976-10981. [PubMed: 1375933]

Calupca MA, Vizzard MA, Parsons R. Origin of pituitary adenylate cyclase-activating polypeptide (PACAP)-immunoreactive fibers innervating guinea pig parasympathetic cardiac ganglia. J Comp Neurol 2000;423:26-39. [PubMed: 10861534]

Cantino D, Mugnaini E. The structural basis for electrotonic coupling in the avian ciliary ganglion. J Neurocytol 1975;4:505-536. [PubMed: 1176998] 
Chang K, Berg D. Nicotinic acetylcholine receptors containing $\alpha 7$ subunits are required for reliable synaptic transmission in situ. J Neurosci 1999;19:3701-3710. [PubMed: 10234002]

Chen M, Pugh P, Margiotta J. Nicotinic synapses formed between chick ciliary ganglion neurons in culture resemble those present on the neurons in vivo. J Neurobiol 2001;47:265-279. [PubMed: 11351338]

Chiba T, Tanaka K, Tatsuoka H, Dun SL, Dun NJ. The synaptic structure of PACAP immunoreactive axons in the intermediolateral nucleus of the rat. Neurosci Lett 1996;214:65-68. [PubMed: 8873133]

Connor JA, Stevens CF. Prediction of repetitive firing behaviour from voltage clamp data on an isolated neurone soma. The Journal of Physiology 1971;213:31-53. [PubMed: 5575343]

Conroy WG, Berg DK. Neurons can maintain multiple classes of nicotinic acetylcholine receptors distinguished by different subunit compositions. J Biol Chem 1995;270:4424-4431. [PubMed: 7876208]

Conroy WG, Nai Q, Ross B, Naughton G, Berg DK. Postsynaptic neuroligin enhances presynaptic inputs at neuronal nicotinic synapses. Dev Biol 2007;307:79-91. [PubMed: 17521624]

Csernus V, Schally A, Groot K. Effect of GHRH and peptides from the vasoactive intestinal peptide family on cAMP production of human cancer cell lines in vitro. Journal of Endocrinology 1999;163:269-280. [PubMed: 10556777]

Cuthbertson S, Zagvazdin YS, Kimble TD, Lamoreaux WJ, Jackson BS, Fitzgerald ME, Reiner A. Preganglionic endings from nucleus of Edinger-Westphal in pigeon ciliary ganglion contain neuronal nitric oxide synthase. Vis Neurosci 1999;16:819-834. [PubMed: 10580718]

DeHaven W, Cuevas J. VPAC receptor modulation of neuroexcitability in intracardiac neurons. Journal of Biological Chemistry 2004;279:40609-40621. [PubMed: 15280371]

del Castillo J, Katz B. Quantal components of the end-plate potential. J Physiol 1954;124:560-573. [PubMed: 13175199]

Drescher MJ, Drescher DG, Khan KM, Hatfieldd JS, Ramakrishnana NA, Abu-Hamdana MD, Lemonniera LA. Pituitary adenylyl cyclase-activating polypeptide (PACAP) and its receptor (PAC1R) are positioned to modulate afferent signaling in the cochlea. Neuroscience 2006;142:139-164. [PubMed: 16876955]

Dryer SE, Chiappinelli VA. Properties of choroid and ciliary neurons in the avian ciliary ganglion and evidence for substance P as a neurotransmitter. J Neurosci 1985;5:2654-2661. [PubMed: 2413183]

Erichsen JT, Karten HJ, Eldred WD, Brecha NC. Localization of substance P-like and enkephalin-like immunoreactivity within preganglionic terminals of the avain ciliary ganglion: light and electron microscopy. J Neurosci 1982;2:994-1003. [PubMed: 6178809]

Ermilov L, Schmalz P, Miller S, Szurszewski J. PACAP modulation of the colon-inferior mesenteric ganglion reflex in the guinea pig. J Physiol 2004;560.1:231-247. [PubMed: 15284351]

Gadea A, López E, López-Colomé A. The adenylate cyclase inhibitor MDL-12330A has a non-specific effect on glycine transport in Müller cells from the retina. Brain Research 1999;838:200-204. [PubMed: 10446333]

Garrel G, Lozach A, Bachir L, Laverriere J-N, Counis R. Pituitary adenylate cyclase-activating polypeptide stimulates nitric oxide synthase type I expression and potentiates the cGMP response to gonadotropin-releasing hormone of rat pituitary gonadotrophs. J Biol Chem 2002;277:46391-46401. [PubMed: 12244042]

Girard B, Keller E, Schutz K, May V, Braas K. Pituitary adenylate cyclase activating polypeptide and $\mathrm{PAC} 1$ receptor signaling increase Homer 1a expression in central and peripheral neurons. Regulatory Peptides 2004;123:107-116. [PubMed: 15518900]

Glass D, Cheng H, Mende-Mueller L, Reed J, Walsh D. Primary structural determinants essential for potent inhibition of cAMP-dependent protein kinase by inhibitory peptides corresponding to the active portion of the heat-stable inhibitor protein. J Biol Chem 1989;264:8802-8810. [PubMed: 2722799]

Guellan G, Mahu J, Mavier P, Berthelot P, Hanoune J. RMI 12330 A, an inhibitor of adenylate cyclase in rat liver. Biochimica and Biophysica Acta 1977;484:465-475.

Halvorsen SW, Berg DK. Affinity labeling of neuronal acetylcholine receptor subunits with an $\alpha$ neurotoxin that blocks receptor function. J Neurosci 1987;7:2547-2555. [PubMed: 3612254] 
Hamelink C, Tjurmina O, Damadzic R, Young W, Weihe E, Lee H-W, Eiden L. Pituitary adenylate cyclase-activating polypeptide is a sympathoadrenal neurotransmitter involved in catecholamine regulation and glucohomeostasis. Proc Natl Acad Sci USA 2002;99:461-466. [PubMed: 11756684]

Han P, Lucero MT. Pituitary adenylate cyclase activating polypeptide reduces A-type K+ currents and caspase activity in cultured adult mouse olfactory neurons. Neuroscience 2005;134:745-756. [PubMed: 16019148]

Han P, Lucero MT. Pituitary adenylate cyclase activating polypeptide reduces expression of Kv1.4 and Kv4.2 subunits underlying A-type $\mathrm{K}(+)$ current in adult mouse olfactory neuroepithelia. Neuroscience 2006;138:411-419. [PubMed: 16426762]

Hannibal J. Pituitary adenylate cyclase-activating peptide in the rat central nervous system: an immunohistochemical and in situ hybridization study. J Comp Neurol 2002;453:389-417. [PubMed: 12389210]

Hess A. Developmental changes in the structure of the synapse on the myelinated cell bodies of the chicken ciliary ganglion. J Cell Biol 1965;25:1-19. [PubMed: 5840798]

Hodgkin A, Huxley A. The dual effect of membrane potential on sodium conductance in the giant axon of Loligo. The Journal of Physiology 1952;116:497-506. [PubMed: 14946715]

Holgert H, Holmberg K, Hannibal J, Fahrenkrug J, Brimijoin S, Hartman BK, Hokfelt T. PACAP in the adrenal gland - relationship with choline acetyltransferase, enkephalin and chromaffin cells and effects of immunological sympathectomy. NeuroReport 1996;8:297-301. [PubMed: 9051799]

Jacob M, Lindstrom J, Berg D. Surface and intracellular distribution of a putative neuronal nicotinic acetylcholine receptor. J Cell Biol 1986;103:205-211. [PubMed: 3522604]

Jayakar, S.; Pugh, P.; Margiotta, J. Neuroscience Meeting Planner. Chicago, IL: Society for Neuroscience; 2009. A-kinase anchoring proteins participate in regulating transmission at neuronal nicotinic synapses. 2009 Online

Johnston, D.; Wu, SM-S. Foundations of cellular neurophysiology. Cambridge: The MIT Press; 1995.

Kanda N, Watanabe S. Intracellular 3',5'-adenosine cyclic monophosphate level regulates house dust mite-induced interleukin-13 production by $\mathrm{T}$ cells from mite-sensitive patients with atopic dermatitis. Journal of Investigative Dermatology 2001;116:3-11. [PubMed: 11168792]

Katsoulis S, Schmidt W, Schwarzhoff R, Fossch U, Jin J-G, Grider J, Makhlouf G. Inhibitory transmission in guinea pig stomach mediated by distinct receptors for pituitary adenylate cyclase-activating peptide. Journal of Pharmacology and Experimental Theraupeutics 1996;278:199-204.

Kennedy M, Beale H, Carlisle H, Washburn L. Integration of biochemical signalling in spines. Nat Rev Neurosci 2005;6:423-434. [PubMed: 15928715]

Kim J, Wei DS, Hoffman DA. Kv4 potassium channel subunits control action potential repolarization and frequency-dependent broadening in rat hippocampal CA1 pyramidal neurones. The Journal of Physiology 2005;569:41-57. [PubMed: 16141270]

Kimura H. Hydrogen sulfide induces cyclic AMP and modulates the NMDA receptor. Biochemical and Biophysical Research Communications 2000;267:129-133. [PubMed: 10623586]

Krishnaswamy A, Cooper E. An activity-dependent retrograde signal induces the expression of the highaffinity choline transporter in cholinergic neurons. Neuron 2009;61:272-286. [PubMed: 19186169]

Lamouche S, Yamaguchi N. Role of PAC1 receptor in adrenal catecholamine secretion induced by PACAP and VIP in vivo. Am J Physiol Regul Integr Comp Physiol 2001;280:R510-R518. [PubMed: 11208582]

Landmesser L, Pilar G. The onset and development of transmission in the chick ciliary ganglion. J Physiol 1972;222:691-713. [PubMed: 4338175]

Légrádi G, Hannibal J, Lechan RM. Association between pituitary adenylate cyclase-activating polypeptide and thyrotropin-releasing hormone in the rat hypothalamus. J Chem Neuroanat 1997;13:265-279. [PubMed: 9412908]

Lin Y, Bennett M. Nitric oxide modulation of quantal secretion in chick ciliary ganglia. Journal of Physiology 1994;481(2):385-394. [PubMed: 7537816]

Liu D-M, Cuevas J, Adams DJ. VIP and PACAP potentiation of nicotinic ACh-evoked currents in rat parasympathetic neurons is mediated by G-protein activation. Eur J Physiol 2000;12:2243-2251. 
Liu QS, Berg DK. Actin filaments and the opposing actions of CaM Kinase II and calcineurin in regulating alpha7-containing nicotinic receptors on chick ciliary ganglion neurons. J Neurosci 1999;19:1028010288. [PubMed: 10575025]

Locknar SA, Calupca MA, Parsons RL. Innervation of guinea-pig stellate ganglia by nitric oxide synthase, cocaine- and amphetamine-regulated transcript protein- and pituitary adenylate cyclase activating polypeptide-immunoreactive fibers. Neuroscience 2002;112:525-533. [PubMed: 12074895]

Loring R, Zigmond R. Ultrastructural distribution of 125I-Toxin F binding sites on chick ciliary neurons: synaptic localization of a toxin that blocks ganglionic nicotinic receptors. Journal of Neuroscience 1987;7:2153-2162. [PubMed: 3612234]

Louise Faber ES. Functions and Modulation of Neuronal SK Channels. Cell Biochem Biophys. 2009

Mabuchi T, Shintani N, Matsumura S, Okuda-Ashitaka E, Hashimoto H, Muratani T, Minami T, Baba A, Ito S. Pituitary adenylate cyclase-activating polypeptide is required for the development of spinal sensitization and induction of neuropathic pain. J Neurosci 2004;24:7283-7291. [PubMed: 15317855]

Margiotta J, Pardi D. Pituitary adenylate cyclase-activating polypeptide type I receptors mediate cyclic AMP-dependent enhancement of neuronal acetylcholine sensitivity. Mol Pharmacol 1995;48:63-71. [PubMed: 7623776]

Margiotta J, Berg D, Dionne V. Cyclic AMP regulates the proportion of functional acetylcholine receptors on chick ciliary ganglion neurons. Proc Natl Acad Sci U S A 1987;84:8155-8159. [PubMed: 2446319]

Margiotta JF, Berg DK. Functional synapses are established between ciliary ganglion neurons in dissociated cell culture. Nature 1982;296:152-154. [PubMed: 7063016]

Martin AR, Pilar G. Quantal components of the synaptic potential in the ciliary ganglion of the chick. J Physiol 1964;175:1-16. [PubMed: 14241156]

McIntosh J, Santos A, Olivera B. Conus peptides targeted to specific nicotinic acetylcholine receptor subtypes. Annu Rev Biochem 1999:68.

Meriney SD, Ford MJ, Oliva D, Pilar G. Endogenous opioids modulate neuronal survival in the developing avian ciliary ganglion. J Neurosci 1991;11:3705-3717. [PubMed: 1660533]

Miyata A, Arimura A, Dahl R, Minamino N, Uehara A, Jiang L, Culler M, Coy D. Isolation of a novel 38 residue-hypothalamic polypeptide which stimulates adenylate cyclase in pituitary cells. Biochem Biophys Res Commun 1989;164:567-574. [PubMed: 2803320]

Mohamed AS, Rivas-Plata KA, Kraas JR, Saleh SM, Swope SL. Src-Class Kinases Act within the Agrin/ MuSK Pathway to Regulate Acetylcholine Receptor Phosphorylation, Cytoskeletal Anchoring, and Clustering. J Neurosci 2001;21:3806-3818. [PubMed: 11356869]

Moro O, Lerner E. Maxadilan, the vasodilator from sand flies, is a specific pituitary adenylate cyclase activating peptide type I receptor agonist. Journal of Biological Chemistry 1997;272:966-970. [PubMed: 8995389]

Moro O, Wakita K, Ohnuma M, Denda S, Lerner E, Tajima M. Functional characterization of structural alterations in the sequence of the vasodilatory peptide maxadilan yields a pituitary adenylate cylcaseactivating peptide type 1 receptor-specific antagonist. Journal of Biological Chemistry 1999;274:23103-23110. [PubMed: 10438479]

Nai Q, Mcintosh JM, Margiotta JF. Relating neuronal nicotinic acetylcholine receptor subtypes defined by subunit composition and channel function. Molecular Pharmacology 2003;63:311-324. [PubMed: 12527802]

Nichol K, Chan N, Davey D, Bennett M. Location of nitric oxide synthase in the developing avian ciliary ganglion. Journal of the Autonomic Nervous System 1995;51:91-102. [PubMed: 7537772]

Oess S, Icking A, Fulton D, Govers R, Müller-Esterl W. Subcellular targeting and trafficking of nitric oxide synthases. Biochem J 2006;396:401-409. [PubMed: 16722822]

Ohnishi T, Okuda-Ashitaka E, Matsumura S, Katano T, Nishizawa M, Ito S. Characterization of signaling pathway for the translocation of neuronal nitric oxide synthase to the plasma membrane by PACAP. J Neurochem 2008;105:2271-2285.

Pardi D, Margiotta JF. Pituitary adenylate cyclase-activating polypeptide activates a phospholipase Cdependent signal pathway in chick ciliary ganglion neurons that selectively inhibits $\alpha 7$-containing nicotinic receptors. J Neurosci 1999;19:6327-6337. [PubMed: 10414962] 
Paysan J, Conroy W, Coggan J, Berg D. The neurofilament infrastructure of a developing presynaptic calyx. J Comp Neurol 2000;425:284-294. [PubMed: 10954846]

Pedarzani P, Stocker M. Molecular and cellular basis of small--and intermediate-conductance, calciumactivated potassium channel function in the brain. Cell Mol Life Sci 2008;65:3196-3217. [PubMed: 18597044]

Peeters K, Gerets HHJ, Arckens L, Vandesande F. Distribution of pituitary adenylate cyclase-activating polypeptide and pituitary adenylate cyclase-activating polypeptide type I receptor mRNA in the chicken brain. J Comp Neurol 2000;423:66-82. [PubMed: 10861537]

Power J, Sah P. Competition between Calcium-Activated K+ Channels Determines Cholinergic Action on Firing Properties of Basolateral Amygdala Projection Neurons. Journal of Neuroscience 2008;28:3209-3220. [PubMed: 18354024]

Pugh P, Margiotta J. Nicotinic acetylcholine receptor agonists promote survival and reduce apoptosis of chick ciliary ganglion neurons. Mol Cell Neurosci 2000;15:113-122. [PubMed: 10673321]

Pugh P, Margiotta J. PACAP support of neuronal survival requires MAPK- and activity-generated signals. Molecular and Cellular Neuroscience 2006;31:586-595. [PubMed: 16431129]

Rasband, W. ImageJ. 1.33u. National Institutes of Health; Bethesda, Maryland USA: 2004.

Rassadi S, Krishnaswamy A, Pié B, McConnell R, Jacob MH, Cooper E. A null mutation for the alpha3 nicotinic acetylcholine (ACh) receptor gene abolishes fast synaptic activity in sympathetic ganglia and reveals that ACh output from developing preganglionic terminals is regulated in an activitydependent retrograde manner. J Neurosci 2005;25:8555-8566. [PubMed: 16162937]

Rathouz MM, Vijayaraghavan S, Berg DK. Acetylcholine differentially affects intracellular calcium via nicotinic and muscarinic receptors on the same population of neurons. J Biol Chem 1995;270:1436614375. [PubMed: 7782297]

Ravdin PM, Berg DK. Inhibition of neuronal acetylcholine sensitivity by $\alpha$-toxins from Bungarus multicinctus venom. Proc Natl Acad Sci USA 1979;76:2072-2076. [PubMed: 287045]

Rawlings SR. At the cutting edge: PACAP, PACAP receptors and intracellular signaling. Mol Cell Endocrinol 1994;101:C5-C9. [PubMed: 9397930]

Richardson RJ, Grkovic I, Anderson CR. Immunohistochemical analysis of intracardiac ganglia of the rat heart. Cell Tissue Res 2003;314:337-350. [PubMed: 14523644]

Role LW, Fischbach GD. Changes in the number of chick ciliary ganglion neuron processes with time in cell culture. Journal of Cell Biology 1987;104:363-370. [PubMed: 3805124]

Rubio M, Curcio C, Chauvet N, Bruses J. Assembly of the N-cadherin complex during synapse formation involves uncoupling of p120-catenin and association with presenilin 1. Mol Cell Neurosci 2005;30:611-623. [PubMed: 16456928]

Sargent PB. Nicotinic receptors concentrated in the subsynaptic membrane do not contribute significantly to synaptic currents at an embryonic synapse in the chicken ciliary ganglion. J Neurosci 2009;29:3749-3759. [PubMed: 19321771]

Scott T, Bennett M. The effect of nitric oxide on the efficacy of synaptic transmission through the chick ciliary ganglion. Br J Pharmacol 1993a;110:627-632. [PubMed: 7694754]

Scott TRD, Bennett MR. The effect of ions and second messengers on long-term potentiation of chemical transmission in avian ciliary ganglia. Br J Pharmacol 1993b;110:461-469. [PubMed: 8220908]

Séguéla P, Wadiche J, Dineley-Miller K, Dani J, Patrick J. Molecular cloning, functional properties, and distribution of rat brain $\alpha 7$ : a nicotinic cation channel highly permeable to calcium. J Neurosci 1993;13:596-604. [PubMed: 7678857]

Shoop RD, Chang KT, Ellisman MH, Berg DK. Synaptically driven calcium transients via nicotinic receptors on somatic spines. J Neurosci 2001;21:771-781. [PubMed: 11157063]

Sonner PM, Stern JE. Functional role of A-type potassium currents in rat presympathetic PVN neurones. J Physiol (Lond) 2007;582:1219-1238. [PubMed: 17525115]

Sumner A, Margiotta JF. Pituitary adenylate cyclase-activating polypeptide (PACAP) alters parasympathetic neuron gene expression in a time-dependent fashion. J Mol Neurosci 2008;36:141156. [PubMed: 18594777]

Sumner A, Przepyszny L, Margiotta J. PACAP localizes to presynaptic terminals and activates CREB in ciliary ganglion neurons. Society for Neuroscience Abstract Viewer 2004;2004:847-814. 
Tompkins J, Ardell J, Hoover D, Parsons R. Neurally released pituitary adenylate cyclase-activating polypeptide enhances guinea pig intrinsic cardiac neurone excitability. The Journal of Physiology 2007;582:87-93. [PubMed: 17495034]

Tornoe K, Hannibal J, Jensen TB, Georg B, Rickelt LF, Andreasen MB, Fahrenkrug J, Holst JJ. PACAP(1-38) as neurotransmitter in the porcine adrenal glands. Am J Physiol Endocrinol Metab 2000;279:E1413-E1425. [PubMed: 11093931]

Ullian EM, McIntosh JM, Sargent PB. Rapid synaptic transmission in the avian ciliary ganglion is mediated by two distinct classes of nicotinic receptors. J Neurosci 1997;17:7210-7219. [PubMed: 9295367]

Vaudry D, Gonzalez B, Basille M, Yon L, Fournier A, Vaudry H. Pituitary adenylate cyclase-activating polypeptide and its receptors: from structure to functions. Pharmacological Reviews 2000;52:269324. [PubMed: 10835102]

Verino S, Amador M, Luetje CW, Patrick J, Dani JA. Calcium modulation and high calcium permeability of neuronal nicotinic acetylcholine receptors. Neuron 1992;8:127-134. [PubMed: 1370370]

Vernallis AB, Conroy WG, Berg DK. Neurons assemble AChRs with as many as 3 kinds of subunits while maintaining subunit segregation among subtypes. Neuron 1993;10:451-464. [PubMed: 8461135]

Wang K, Hackett JT, Cox ME, Van Hoek M, Lindstrom JM, Parsons SJ. Regulation of the neuronal nicotinic acetylcholine receptor by SRC family tyrosine kinases. J Biol Chem 2004;279:8779-8786. [PubMed: 14679211]

Wilson Horch H, Sargent P. Perisynaptic surface distribution of multiple classes of nicotinic acetylcholine receptors on neurons in the chicken ciliary ganglion. J Neurosci 1995;15:7778-7795. [PubMed: 8613719]

Woo, S.; Margiotta, J. PACAP elevates calcium in ciliary ganglion neurons by PAC1-mediated signaling. 8th International Symposium for VIP, PACAP and Related Peptides; Manchester, VT. 2007.

Zhou X, Nai Q, Chen M, Dittus JD, Howard MJ, Margiotta JF. Brain-derived neurotrophic factor and trkB signaling in parasympathetic neurons: relevance to regulating $\alpha 7$-containing nicotinic receptors and synaptic function. Journal of Neuroscience 2004;24:4340-4350. [PubMed: $15128848]$ 


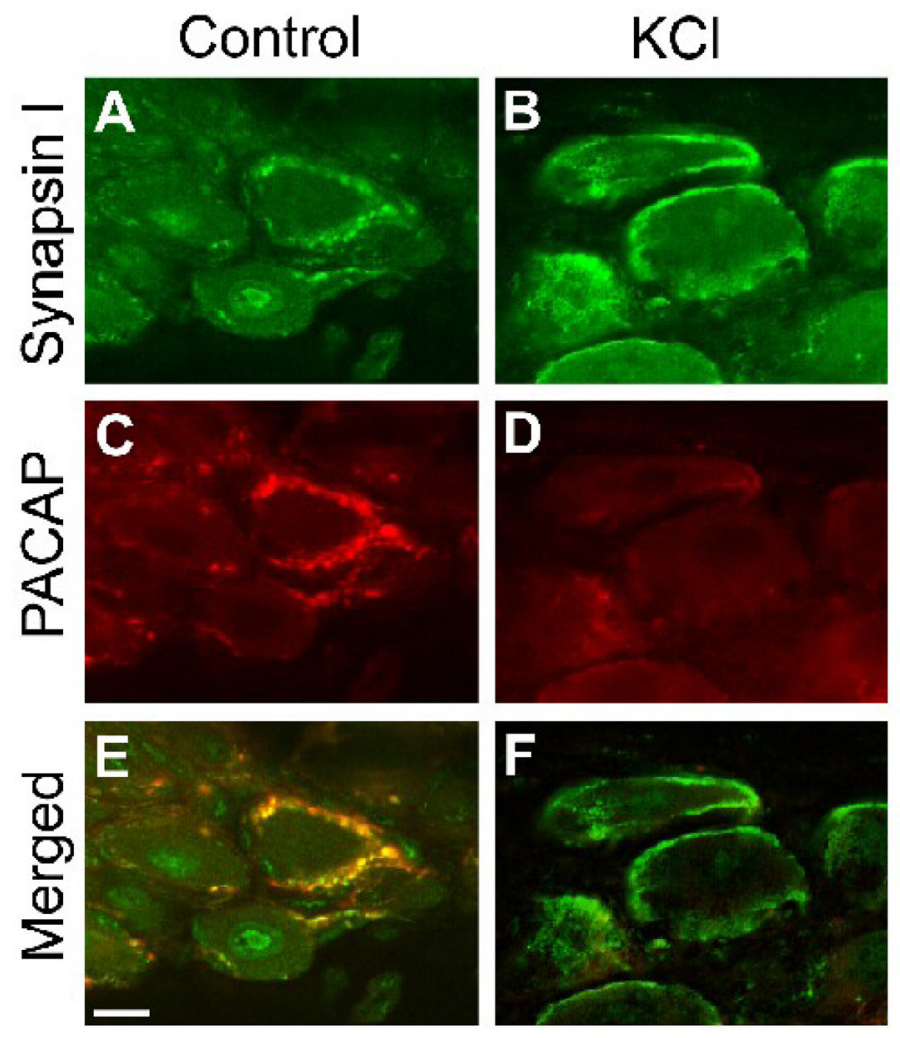

Figure 1.

PACAP localizes to presynaptic terminals and is released by depolarization. Left: Synapsin I (A, green) and PACAP (B, red) immunostaining co-localize $(\mathbf{C}$, yellow) in presynaptic calyces that contact ciliary ganglion neurons. Right: After incubation with depolarizing levels of $\mathrm{KCl}$ (50 mM, $30 \mathrm{~min}$ ), Synapsin I immunostaining remains (D) while PACAP immunostaining disappears from the calyces $(\mathbf{E}, \mathbf{F})$. Confocal images were acquired from E19 ciliary ganglia and depict representative, $1 \mu \mathrm{m}$ optical sections. Scale bar, $20 \mu \mathrm{m}$. 
A

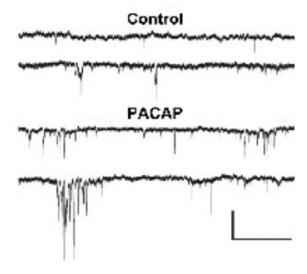

B

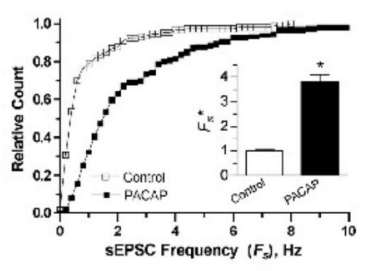

C

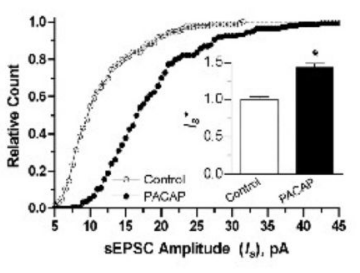

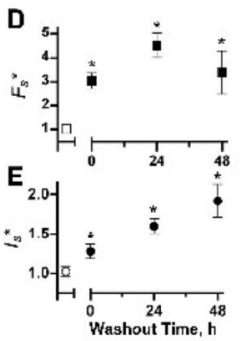

Figure 2.

PACAP enhances transmission at nicotinic synapses on CG neurons. A. Representative sEPSCs are depicted for sham- and PACAP-treated (100 nM, $15 \mathrm{~min})$ CG neurons from the same culture. In this experiment, PACAP increased mean sEPSC frequency $\left(F_{s}\right)$ from 1.5 to $7.7 \mathrm{~Hz}$, and mean sEPSC amplitude $\left(I_{S}\right)$ from 22.1 to $31.5 \mathrm{pA}$ (n $=5$ neurons for both). Calibrations, $10 \mathrm{pA} / 100 \mathrm{~ms}$. B and C. Cumulative distributions of $F_{S}(\mathbf{B})$ and $I_{S}(\mathbf{C})$ values obtained from PACAP-treated neurons $(\boldsymbol{\bullet}, \bullet ; \mathrm{n}=146)$ are plotted with accompanying values from sham-treated control neurons $(\square, \circ ; \mathrm{n}=154)$ tested in the same 30 experiments.

Significant rightward shifts in both $F_{s}$ and $I_{s}$ distributions are associated with PACAP treatment ( $p<0.02$, by Kolmogorov-Smirnov test). The bar graph insets show that the PACAP treated neurons displayed mean sEPSC frequency and amplitude values that were, $3.8 \pm 0.3$ and 1.4 \pm 0.1 times larger $\left(F_{s}{ }^{*}\right.$ and $I_{s}{ }^{*}$, respectively) than those of sham-treated controls $(p<0.05$ for both, $t$-test). $\mathbf{D}$ and $\mathbf{E}$. Brief PACAP exposure produces persistent increases in SEPSC frequency and amplitude. Washout kinetics were assessed by comparing $F_{s}^{*}(\mathbf{D})$ and $I_{s}^{*}(\mathbf{E})$ at the indicated times after $15 \mathrm{~min}$ PACAP $(100 \mathrm{nM})$ treatment $(\boldsymbol{\bullet}, \bullet)$ relative to sham treatments $(\square$, ○). CG neurons were treated with PACAP for 15 minutes on the $3^{\text {rd }}$ (48 h wash), $4^{\text {th }}$ ( $24 \mathrm{~h}$ wash), or $5^{\text {th }}$ ( $<30 \mathrm{~min}$ wash) day in culture, or not at all. Both $F_{s}{ }^{*}$ and $I_{s}{ }^{*}$ remain elevated in PACAP- compared to sham-treated control neurons for at least $48 \mathrm{~h}$. In this and subsequent figures, value asterisks $(*)$ indicate a significant change $(p<0.05)$ relative to controls. 

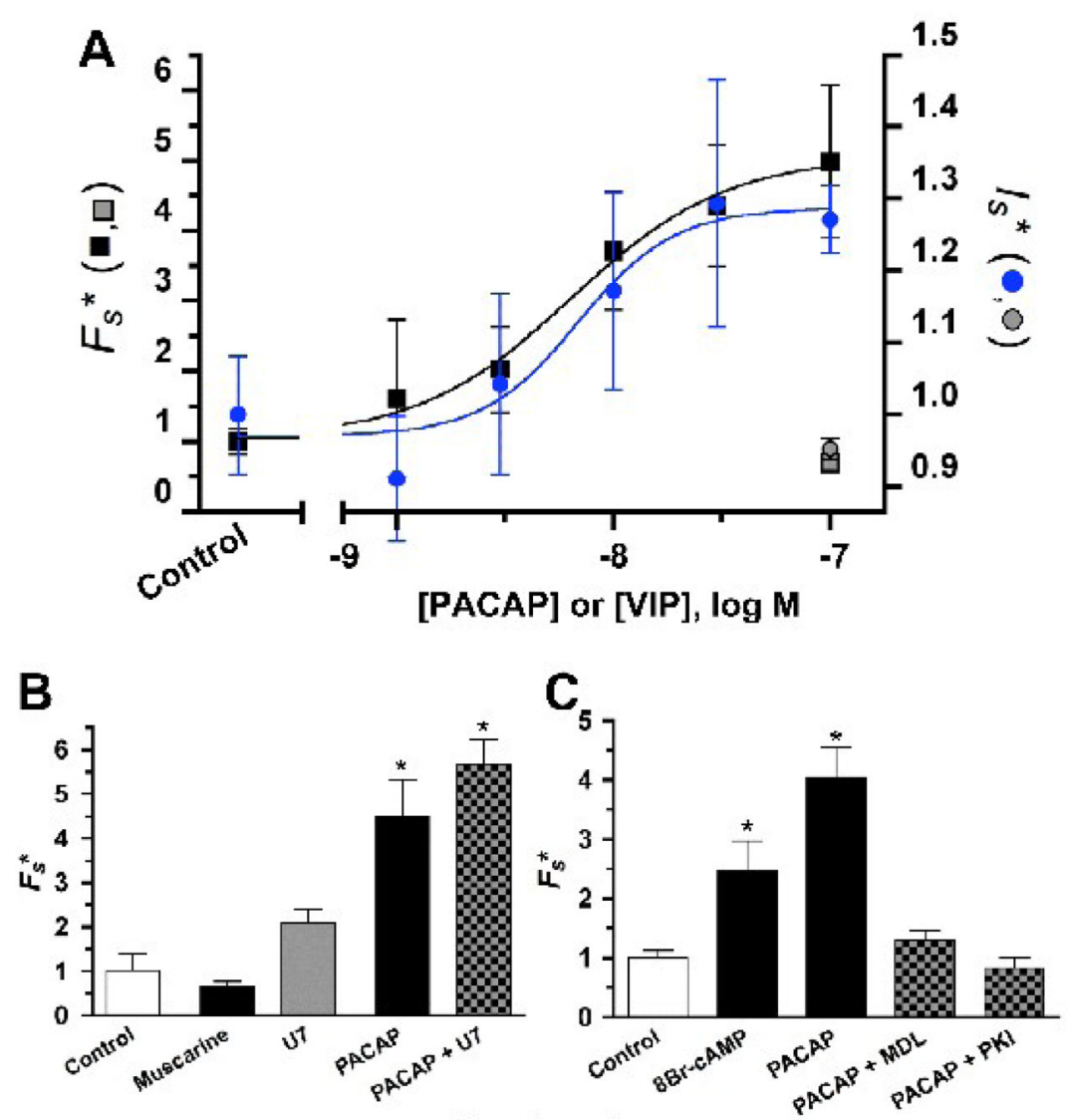

Treatment

Figure 3.

PACAP regulates synaptic function via $\mathrm{PAC}_{1} \mathrm{R}$ activation of AC-dependent signaling. A. PACAP (1-100 nM, $\left.15 \mathrm{~min}, 37^{\circ} \mathrm{C}\right)$ produced dose-dependent increases in sEPSC frequency $\left(F_{s}{ }^{*}, \mathbf{m}\right.$, black line, left axis) and amplitude $\left(I_{s}{ }^{*}, \bullet\right.$, blue line, right axis) predicting nanomolar $\mathrm{EC}_{50}$ values for both $(6.4 \pm 2.2 \mathrm{nM}$ and $6.9 \pm 2.5 \mathrm{nM}$, respectively) while VIP $(100 \mathrm{nM})$ failed to increase either $F_{s}{ }^{*}$ (A) or $I_{s}{ }^{*}$ (A). Both findings are consistent with a requirement for $\mathrm{PAC}_{1} \mathrm{R}$ over VPACR activation. B. PLC is dispensable for PACAP-mediated changes. Activation of PLC signaling with muscarine $(100 \mu \mathrm{M})$ failed to alter $F_{s} *$. Similarly, PLC inhibition with U73122 $(1 \mu \mathrm{M}, \mathrm{U} 7)$ failed to change $F_{s} *$ or to prevent PACAP from enhancing $F_{s}{ }^{*}$. Similar effects on sEPSC amplitudes $\left(I_{s}^{*}\right)$ were observed (data not shown). C. Cyclic AMP, AC and PKA are required for sustained PACAP modulation of sEPSCs. 8Br-cAMP (2 $\mathrm{mM})$ mimicked PACAP's actions while AC inhibition with MDL12330A (+MDL, $1 \mu \mathrm{M})$ or PKA with myristolated PKI (+PKI, $1 \mu \mathrm{M})$ reduced the ability of PACAP $(100 \mathrm{nM}, 15 \mathrm{~min})$ to enhance sEPSC frequency $\left(F_{s}^{*}\right)$. Similar effects on sEPSC amplitudes $\left(I_{s}^{*}\right)$ were observed, and neither MDL12330A nor myristolated PKI altered sEPSC frequency or amplitude when applied alone (data not shown). 
A

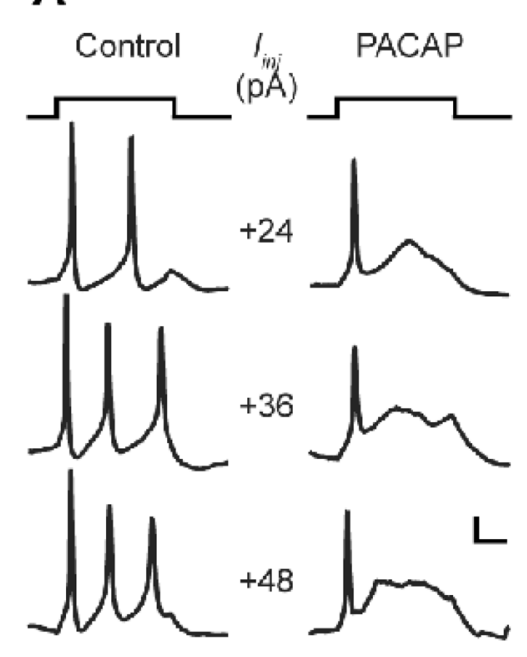

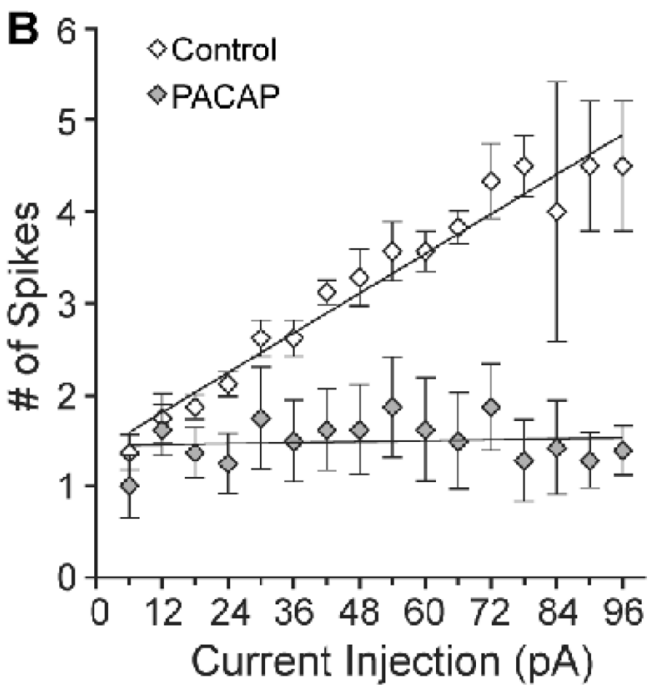

Figure 4.

PACAP reduces the excitability of CG neurons. A. Example records depict increased action potential firing associated with application of progressively larger depolarizing currents in sham-treated control neurons (left) while firing was depressed after PACAP treatment (100 $\mathrm{nM}, 15 \mathrm{~min}$, right). Traces show voltage recordings from neurons in whole-cell current clamp mode with 200 ms duration current pulses (bars above records) applied as indicated $\left(I_{i n j}\right)$ at $0.1 \mathrm{~Hz}$. B. The number of action potentials increased as a function of the applied depolarizing current intensity in sham-treated control neurons $(\diamond, n=8)$ but not in PACAP-treated neurons $(\checkmark, \mathrm{n}=8)$. Linear regression analyses predicted slopes of $0.039 \mathrm{pA}^{-1}$ for control and and 0.001 $\mathrm{pA}^{-1}$ for PACAP-treated neurons $(p<0.0001, F$ test). 
A
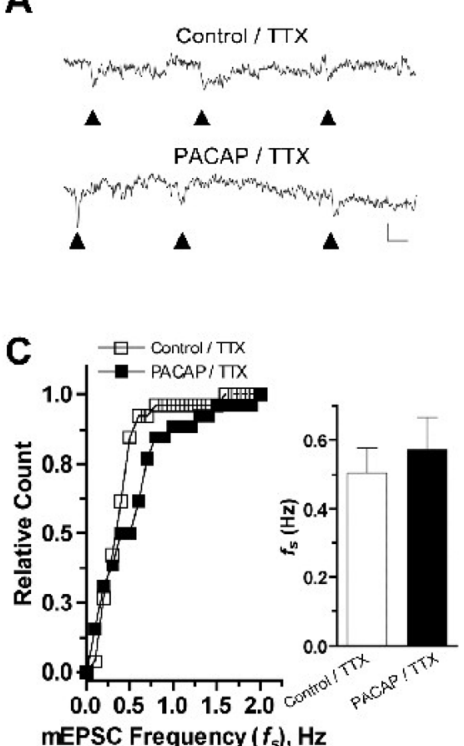

E

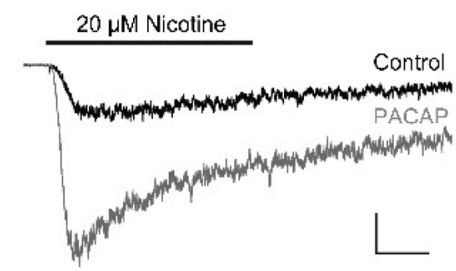

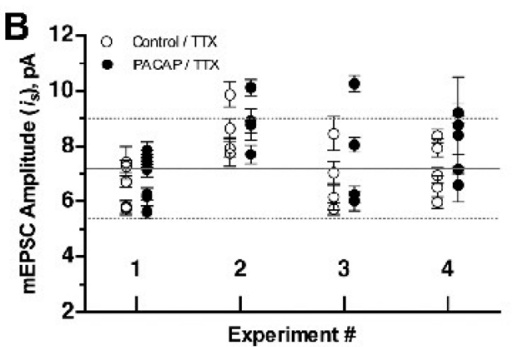
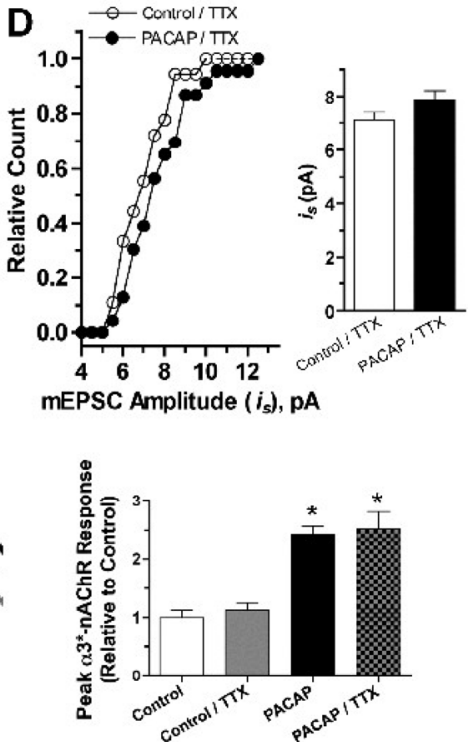

Figure 5.

PACAP fails to influence $\alpha 3^{*}$-nAChR mediated mEPSC amplitudes $\left(i_{s}\right)$ while enhancing somatic membrane $\alpha 3 *$-nAChR responses. A. Example records showing spontaneous mEPSCs ( $\mathbf{\Delta}$ ) with similar amplitudes in control (top) and PACAP-treated (bottom, $100 \mathrm{nM}, 15 \mathrm{~min}$ ) CG neurons from the same experiment. Scale bars, $10 \mathrm{pA} / 10 \mathrm{msec}$. B. Stability of mean mEPSC amplitudes in control $(\circ, \mathrm{n}=19,807$ events $)$ and PACAP-treated neurons $(\bullet, \mathrm{n}=26,1273$ events) from four experiments. Solid line indicates the mean mEPSC amplitude (7.2 pA) \pm 1 SD (1.8 pA; dashed lines) from 37 neurons in 9 experiments. C and D show detailed comparisons of mean mEPSC frequencies $(\mathbf{C})$ and amplitudes $(\mathbf{D})$ from PACAP-treated $(\bullet, \mathbf{\square})$ and control $(\circ, \square)$ CG neurons acquired in the same 4 experiments as in B. Cumulative distributions reveal that PACAP treatments shift mEPSC frequencies $\left(f_{s}\right.$, left) to slightly higher maximal values ( $p<0.05$, KS test) without detectably changing mEPSC amplitudes $\left(i_{s}\right.$, right, $p>0.6, \mathrm{KS}$ test). Bar plots show that mean $( \pm \mathrm{SEM}) f_{s}$ (left) and $i_{S}$ (right) values after PACAP treatment $(\mathrm{n}=23 ; 0.57 \pm 0.09 \mathrm{~Hz}$ and $7.9 \pm 0.3 \mathrm{pA}$, respectively) were indistinguishable from those obtained from matched controls $(n=18 ; 0.39 \pm 0.04 \mathrm{~Hz}$ and $7.1 \pm 0.3 \mathrm{pA}$, respectively) tested in parallel ( $p>0.09$ for both, $t$-test). Results in $\mathbf{A}-\mathbf{D}$ were obtained in the presence of $1 \mu \mathrm{M}$ TTX. E. PACAP treatment increases inward currents generated by plasma membrane $\alpha 3 *$-nAChRs. In these experiments, $\alpha 3^{*}$-nAChRs were isolated by pre-incubating cultures in $\alpha \operatorname{Bgt}(50 \mathrm{nM}, 1 \mathrm{~h}$ ) (Nai et al., 2003; Zhou et al., 2004) with toxin exposure continued throughout the indicated treatments. Records (left) depict membrane $\alpha 3 *$-nAChR currents acquired from sham- and PACAP-treated neurons (black and gray traces, respectively) that were induced by $20 \mu \mathrm{M}$ nicotine delivered by rapid pressure microperfusion (1 sec @ $7.5 \mathrm{psi}$; top bar). Scale bars: $200 \mathrm{pA} / 250 \mathrm{msec}$. Bar graph (right) shows that peak $\alpha 3 *-\mathrm{nAChR}$ responses $(\mathrm{pA} / \mathrm{pF})$ induced by nicotine in PACAP-treated neurons (black bar) were $2.4 \pm 0.1$ times larger than 
those obtained from sham-treated control neurons from the same experiments ( $\mathrm{n}=4$ for each). Following TTX $(1 \mu \mathrm{M})$ pre-incubation and inclusion in the recording solution, PACAP

treatment (check bar) similarly increased nicotine induced peak $\alpha 3 *$-nAChR responses to 2.5 \pm 0.4 times control values ( $\mathrm{n}=4$ for each). TTX treatment alone had no detectable effect. Asterisks indicate a significant difference in $\alpha 3^{*}$-nAChR response relative to controls ( $p<$ 0.01 , ANOVA). 

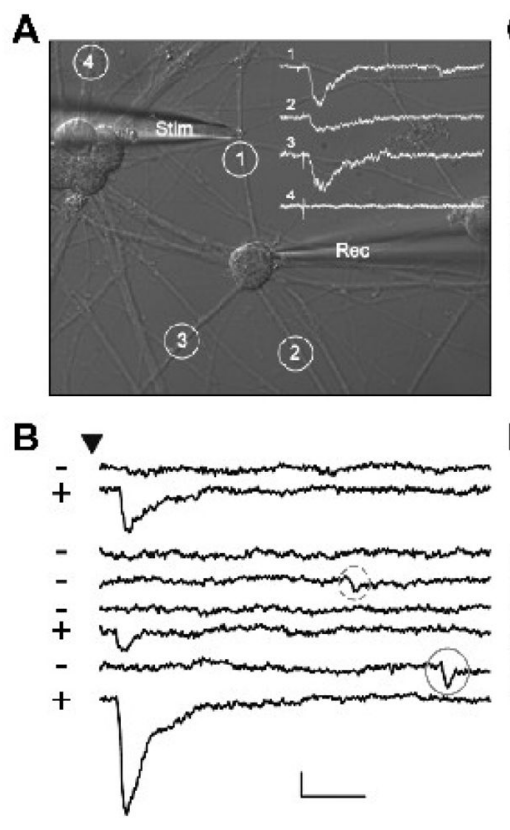

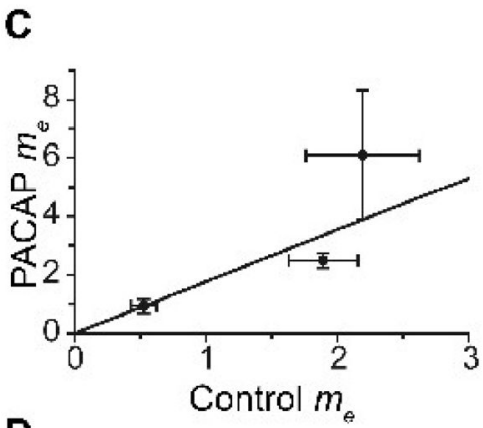

D

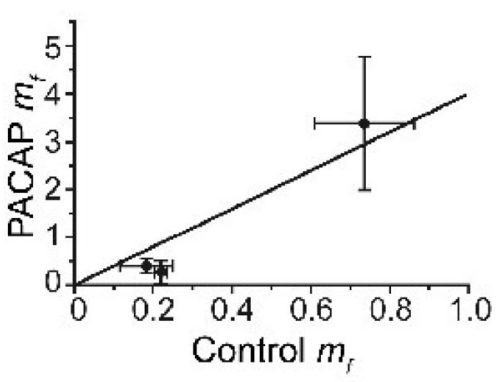

Figure 6.

Evoked EPSCs and quantal analysis in CG neuron cultures. A. Stimulating neurite fasicles (Stim, 1-4) converging onto a CG neuron soma "hub" (center, recording pipette at right, Rec) reliably evokes somatic EPSCs (1-3), which are absent when a non-convergent fasicle is stimulated (4). B. Sample recordings show that single fasicle stimuli $(\boldsymbol{\nabla})$ either evoke $(+)$ or fail to evoke (-) a short-latency EPSC in the associated "hub" soma. Spontaneous sEPSCs (solid) and mEPSCs (dashed) are circled. Calibrations: 20 pA/10 ms. C-D. Quantal content was assessed for individual control and PACAP-treated neurons using $m_{e}=I_{e} / i_{e}$ or $m_{f}=l n$ $\left(N_{T} / N_{0}\right)$. In $\mathbf{C}$ and $\mathbf{D}$, respectively, each point represents the average $m_{e}$ or $m_{f}$ value $( \pm$ SEM, $\mathrm{n}=2$ to 8 neurons for each treatment per day) from 3 experiments. Linear regression lines drawn through the points $\left(\mathrm{r}^{2} \approx 0.8\right)$ both had non-zero positive slopes ( $\mathrm{p}<0.001$ by $F$-test, slope $\left.=\Delta m=\Delta m_{P A C A P} / \Delta m_{\text {Control }}\right)$ indicating that PACAP treatment increased $m_{e}$ and $m_{f}$ by $2.2 \pm 0.5$ - and $4.2 \pm 0.7$-fold, respectively. Quantal content comparisons within experiments yielded a similar trend predicting $m_{e}$ and $m_{f}$ values for PACAP treated neurons that were, respectively, $1.8 \pm 0.3$ - and $2.7 \pm 0.7$-times higher than those obtained from sham treated control neurons tested in parallel (Table 1). 


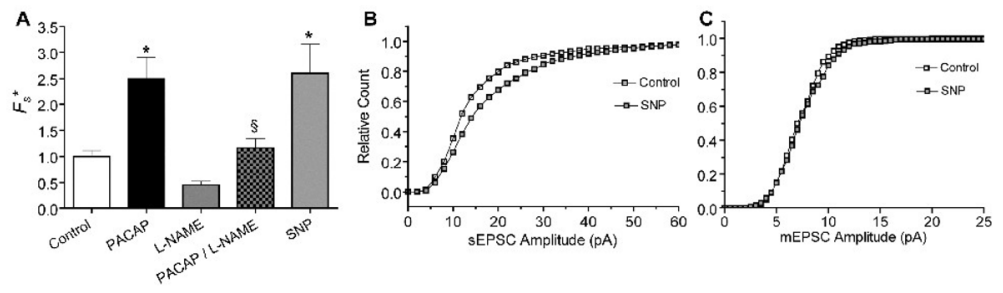

Figure 7.

PACAP enhances synaptic activity via NOS activation and NO production. A. Effects of NOS inhibition and NO production. The stimulation of sEPSC frequency $\left(F_{s}^{*}\right)$ normally seen for PACAP-treated neurons (black bar) relative to sham controls tested in parallel (white bar, $\mathrm{n}=$ 5 for each) was blocked after inhibiting NOS with L-NAME $(100 \mu \mathrm{M}$, checked bar, $\mathrm{n}=4)$ while L-NAME alone had no discernable effect (gray bar, $\mathrm{n}=4$ ). Mimicking NOS activation with the NO donor SNP $(100 \mu \mathrm{M}$, green bar, $\mathrm{n}=8)$ increased $F_{S}$ to a level significantly above untreated controls $(\mathrm{n}=8)$ and indistinguishable from that achieved after PACAP treatment. Asterisks (*) indicate $p<0.05$ versus Control; $\S$ indicates $p<0.05$ versus PACAP treatment alone. $F_{s}{ }^{*}$ values obtained after L-NAME treatment were indistinguishable from those obtained after control or PACAP/L-NAME treatments ( $p>0.05$ for both). B, C. Like PACAP, NO production increases quantal content inferred from sEPSCs. SNP treatment (green filled boxes) significantly increased $I_{S}$ relative to untreated controls (open boxes; $\mathrm{n}=8$ for each), but left $i_{s}$ unchanged relative to controls ( $\mathrm{n}=9$ for each). The distribution of sEPSC amplitudes $\left(I_{s}\right.$, B $)$ exhibited a significant rightward shift after SNP treatment compared to controls (2113 and 1375 events from 8 PACAP-treated and 8 control neurons, respectively, $p<0.01, \mathrm{KS}$ test), while mEPSC amplitudes $\left(i_{s}, \mathbf{C}\right)$ remained unaltered (437 and 467 events from 9 PACAPtreated and 9 control neurons, respectively, $p=0.078$, KS test) thereby predicting increased $m_{S}\left(=I_{S} / i_{S}\right)$. 

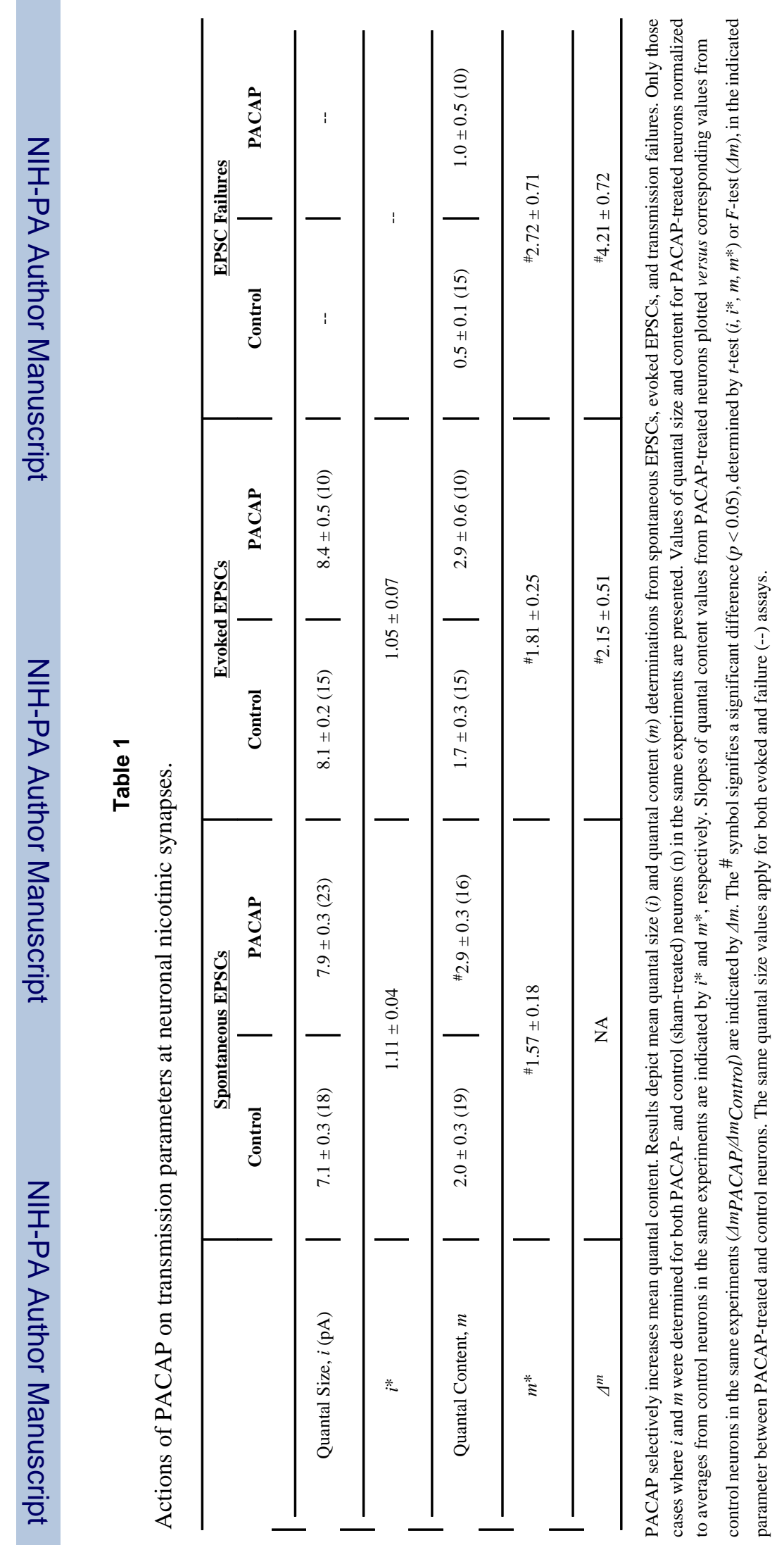

Mol Cell Neurosci. Author manuscript; available in PMC 2011 February 1. 